Article

\title{
Vinification without Saccharomyces: Interacting Osmotolerant and "Spoilage" Yeast Communities in Fermenting and Ageing Botrytised High-Sugar Wines (Tokaj Essence)
}

\author{
Hajnalka Csoma ${ }^{1}$, Zoltán Kállai ${ }^{2}$, Zsuzsa Antunovics ${ }^{1}$, Kinga Czentye ${ }^{1}$ and Matthias Sipiczki ${ }^{1, *(D)}$ \\ 1 Department of Genetics and Applied Microbiology, University of Debrecen, 4032 Debrecen, Hungary; \\ hajnalka.csoma@outlook.com (H.C.); lepkekutato@gmail.com (Z.A.); czkinga12@gmail.com (K.C.) \\ 2 Research Institute for Viticulture and Oenology, 3915 Tokaj, Hungary; kallai.zoltan@tarcalkutato.hu \\ * Correspondence: gecela@post.sk or lipovy@gmx.com
}

check for

updates

Citation: Csoma, H.; Kállai, Z.; Antunovics, Z.; Czentye, K.; Sipiczki, M. Vinification without Saccharomyces: Interacting Osmotolerant and "Spoilage" Yeast Communities in Fermenting and Ageing Botrytised High-Sugar Wines (Tokaj Essence).

Microorganisms 2021, 9, 19.

https://dx.doi.org/10.3390/

microorganisms 9010019

Received: 29 November 2020

Accepted: 19 December 2020

Published: 23 December 2020

Publisher's Note: MDPI stays neutral with regard to jurisdictional claims in published maps and institutional affiliations.

Copyright: (C) 2020 by the authors. Licensee MDPI, Basel, Switzerland. This article is an open access article distributed under the terms and conditions of the Creative Commons Attribution (CC BY) license (https: / / creativecommons.org/ licenses/by/4.0/).

\begin{abstract}
The conversion of grape juice to wine starts with complex yeast communities consisting of strains that have colonised the harvested grape and/or reside in the winery environment. As the conditions in the fermenting juice gradually become inhibitory for most species, they are rapidly overgrown by the more adaptable Saccharomyces strains, which then complete the fermentation. However, there are environmental factors that even Saccharomyces cannot cope with. We show that when the sugar content is extremely high, osmotolerant yeasts, usually considered as "spoilage yeasts", ferment the must. The examination of the yeast biota of 22 botrytised Tokaj Essence wines of sugar concentrations ranging from 365 to $752 \mathrm{~g} \cdot \mathrm{L}^{-1}$ identified the osmotolerant Zygosaccharomyces rouxii, Candida (Starmerella) lactis-condensi and Candida zemplinina (Starmerella bacillaris) as the dominating species. Ten additional species, mostly known as osmotolerant spoilage yeasts or biofilm-producing yeasts, were detected as minor components of the populations. The high phenotypical and molecular (karyotype, mtDNA restriction fragment length polymorphism (RFLP) and microsatellite-primed PCR (MSP-PCR)) diversity of the conspecific strains indicated that diverse clones of the species coexisted in the wines. Genetic segregation of certain clones and interactions (antagonism and crossfeeding) of the species also appeared to shape the fermenting yeast biota.
\end{abstract}

Keywords: yeast; Zygosaccharomyces; Candida; wine; fermentation; osmotolerant; genetic diversity; antagonism; Tokaj

\section{Introduction}

The conversion of grape must to wine is the result of the joint activities of multiple yeast species. The spontaneous fermentation process starts with a mixed community of yeast species that are determined primarily by the yeast populations colonising the harvested grape and the winery environment (e.g., [1-3]). The composition of the community rapidly changes in the fermenting must because most non-Saccharomyces yeasts die and strains of the species Saccharomyces cerevisiae, Saccharomyces uvarum and genomic chimeras of various Saccharomyces species take the lead and drive the fermentation to completion. The success of the Saccharomyces strains is attributable to their overall better resistance and adaptability to the rapidly changing environmental factors (e.g., high levels of ethanol and organic acids, low $\mathrm{pH}$ values, scarce oxygen availability and depletion of certain nutrients) compared to non-Saccharomyces yeasts (reviewed in [1,4]). Only a few non-Saccharomyces strains can persist until the end of fermentation (e.g., [5-10]).

The non-Saccharomyces species can display either beneficial or detrimental ("spoiling") activities, but many of them have both. The latter play positive roles in certain phases of the fermentation process and negative roles in other phases or have a positive impact on the quality of certain types of wines and a negative effect on the quality and stability 
of other types of wines (for recent reviews, see [11-15]). Nevertheless, for practical reasons, the yeasts that can cause problems are usually considered spoilage microorganisms, even if they also have properties that can beneficially modify the sensory quality of the wine. The most frequently occurring yeasts with (at least occasional) wine spoilage effects belong to the species Brettanomyces bruxellensis (Dekkera bruxellensis) [16,17], Zygosaccharomyces bailii (Saccharomyces bailiii), Z. rouxii (Saccharomyces rouxii, Saccharomyces osmophilus), hybrids/chimeras of various Zygosaccharomyces species (e.g., [18-22]), Candida lactis-condensi (Torula lactis-condensi, Torulopsis lactis-condensi, Starmerella lactis-condensi) [23], Candida zemplinina (Saccharomyces bacillaris, Torulopsis bacillaris, Starmerella bacillaris) [10,23,24], Hanseniaspora osmophila (Kloeckeraspora osmophila, Kloeckera corticis) [25], Pichia anomala (Candida pelliculosa, Hansenula anomala) [26], Pichia membranifaciens (Candida valida) [27-29], Rhodotorula mucilaginosa [30], Saccharomycodes ludwigii [31,32], Kregervanrija fluxuum (Pichia fluxorum) [29] and Candida apicola [12]. Several of these species are osmotolerant or even osmophilic (e.g., [6,24,33-35]) and pose a threat to the stability of aging sweetened wines and wines containing higher levels of residual sugar, as well as to other high-sugar beverages, fruit juice concentrates, sugar confectionery products, honey, dried fruit and jams (e.g., [36-40]).

Although non-Saccharomyces yeasts can occasionally become dominating, they are generally not capable of completing alcoholic fermentation on their own. In this study, we showed that osmotolerant yeasts that are considered unwanted spoiling organisms in wine-making can ferment high-sugar botrytised grape must without the contribution of Saccharomyces. Musts prepared from botrytised (nobly rotten) grapes usually have extremely high concentrations of sugars, which cannot be completely converted to ethanol and other metabolites during fermentation (for recent reviews, see [41,42]). Noble rotting requires specific microclimatic conditions that allow for the destruction of the skins and the internal structures of the ripening berries by the invading hyphae of Botrytis cinerea but prevents the fungus from causing malevolent sour rotting. Instead, the berries lose water through the Botrytis-generated lesions. Due to water evaporation, the sugar concentration in the juice of the shrivelling grapes increases drastically and the must prepared from these grapes will have a high sugar content [43]. More than 30 wine regions located in the cooler part of the wine-producing zones around the globe are known to have climatic conditions that allow for noble rot and the production of botrytised and/or Botrytis-affected wines [44]. The region with the longest documented history of botrytised wine production in Europe is Tokaj (Tokay) $[45,46]$. One of the most specific Tokaj wine brands that is unique in the world is Essence (Eszencia, Esencia), which is made from the juice that seeps out spontaneously from the harvested nobly rotten berries stored in large containers [47]. Its sugar content can exceed $700 \mathrm{~g} \cdot \mathrm{L}^{-1}$, which is a concentration that is inhibitory to most yeasts occurring in various stages of the fermentation of other types of wines. Because of the extremely high sugar content, Essence fermentation lasts for years and produces little more than 5 to $7 \%$ alcohol $[47,48]$. Preliminary studies of our laboratory have detected strains of the osmotolerant "wine spoilage" species Z. bailii, Z. rouxii, C. lactis-condensi and C. zemplinina in samples of Tokaj Essence wines [49] but neither the composition of the yeast populations nor the properties of the fermenting strains were investigated. Since then, the latter species have been transferred to the genus Starmerella under the new names S. lactis-condensi and S. bacillaris $[50,51]$ but the "previous names" were retained as valid synonyms and have remained widely used in the literature. Because of their widespread use and because the taxonomic description of the species C. zemplinina was based on Tokaj yeasts, we will use the old species names in this study.

Here, we report on an investigation of the yeast biota of 28 Essence wines. The composition of wine yeast microflora can be investigated using culture-dependent and cultureindependent methods (for a review, see [52]). Neither can explore the entire complexity of the active yeast communities. The former cannot detect yeasts that do not grow on laboratory media or are in the so-called VBNC (viable but not culturable) state. The latter does not distinguish between the DNA of living and dead yeasts and thus overestimates the diversity of the yeast community that is actively participating in fermentation [53]. To overcome 
this problem, certain studies applied reverse-transcription PCR, which amplifies copies of RNAs (e.g., [54-56]). This method is based on the assumption that only living cells have detectable RNAs. However, as RNA can be easily degraded by contaminating RNAse, the reproducibility of the results can be low. Because of these shortcomings of the cultureindependent methods, we opted for a culture-dependent procedure. Another advantage of culture-dependent methods is that the isolated yeasts can be subjected to genetic and physiological investigation. The taxonomic analysis of high numbers of isolates identified 13 species, all of which are known as "wine spoilage yeasts". Three of them, Z. rouxii, C. lactis-condensi and C. zemplinina dominated the majority of the wines, indicating that these yeasts run the fermentation. The rest of the species were present sporadically as minor subpopulations, including four film-forming yeasts. The populations of the dominating yeasts consisted of clones differing in phenotypic properties and molecular patterns and were prone to segregation.

\section{Materials and Methods}

\subsection{Culture Media and Reference Yeast Strain}

Two types of solid media were used for yeast isolation and the maintenance of the isolates: YEA2 (1\% yeast extract, $2 \%$ glucose and 2\% agar) and YEA35 (YEA supplemented with $35 \%$ glucose). The liquid media were YEL (YEA2 without agar) and YPGL (YEL supplemented with $1 \%$ peptone). SMA [ $1 \%$ glucose; $2 \%$ agar; $0.5 \%\left(\mathrm{NH}_{4}\right)_{2} \mathrm{SO}_{4} ; 0.01 \%$ $\mathrm{KH}_{2} \mathrm{PO}_{4}, \mathrm{MgSO}_{4}$ and vitamins] containing $1 \%$ carbon source or $0.5 \%$ nitrogen source to be tested instead of glucose or $\left(\mathrm{NH}_{4}\right)_{2} \mathrm{SO}_{4}$ was used for the phenotypic clustering of isolates. $\mathrm{H}_{2} \mathrm{~S}$ production was tested on BiGGY Agar (Bismuth Sulphite Glucose Glycine Yeast; Oxoid). Acid production was examined on Custer's chalk medium (0.5\% yeast extract, $5 \%$ glucose, $2 \%$ agar, $0.5 \%$ calcium carbonate, $\mathrm{pH} 5.0$ ) [57]. The composition of the medium (synthetic must) used in the microplate experiments was: $0.5 \% \mathrm{KH}_{2} \mathrm{PO}_{4}, 0.04 \%$ $\mathrm{MgSO}_{4} \cdot 7 \mathrm{H}_{2} \mathrm{O}, 0.1 \%$ yeast extract and $0.1 \%$ vitamin solution (according to [58]), $\mathrm{pH} 3.5$ (adjusted with tartaric acid) supplemented with various amounts of glucose and fructose in a 1:1 proportion. Z. rouxii CBS $732^{\mathrm{T}}$ was used as a reference strain in the investigation of the molecular diversity of the $Z$. rouxii isolates.

\subsection{Sample Collection and Analysis}

Twenty-eight Essence wines in various stages of fermentation and aging were sampled in February and March 2020 in wineries of the Tokaj region (Table 1). Nine sampled wines were in bottled lots prepared for commercial distribution. Nineteen samples were taken from batches that were fermenting and/or ageing in stainless steel containers, $50 \mathrm{~L}$ glass balloons, ceramic amphoras or oak barrels at $11-15{ }^{\circ} \mathrm{C}$. The samples were kept in the laboratory at $12{ }^{\circ} \mathrm{C}$.

The $\mathrm{pH}$ and the alcohol, total sugar, titratable acid, $\mathrm{SO}_{2}$, acetic acid and extract contents were measured according to the methods laid down in the Commission Regulation (EEC) No. 2676/90 of the European Union [59]. When the sample volume was not enough for these analytical methods, a Bruker Alpha FTIR spectrometer (Bruker Optic GmbH, Ettlingen, Germany) was used and the results were processed with the Bruker OPUS software. The viable yeast cell number (number of CFUs: colony-forming units) was determined by diluting the samples and spreading aliquots on YEA2 plates. The number of colonies was counted after 6 days of incubation at room temperature. 
Table 1. List and properties of samples.

\begin{tabular}{|c|c|c|c|c|c|c|c|c|c|c|c|c|c|}
\hline \multirow[b]{2}{*}{ Sample } & \multirow{2}{*}{$\begin{array}{l}\text { Location } \\
\text { of Winery }\end{array}$} & \multirow[b]{2}{*}{ Vintage } & \multirow[b]{2}{*}{ Stored in ${ }^{1}$} & \multirow{2}{*}{$\begin{array}{l}\text { Reducing } \\
\text { Sugar g/L }\end{array}$} & \multirow[b]{2}{*}{ Alcohol\% } & \multicolumn{2}{|c|}{ Extract } & \multirow[b]{2}{*}{$\mathrm{pH}$} & \multicolumn{2}{|c|}{ Acid } & \multicolumn{2}{|c|}{$\mathrm{SO}_{2}{ }^{2}$} & \multirow{2}{*}{$\begin{array}{c}\mathrm{CFU}^{3} \\
\left(10^{8} / \mathrm{mL}\right)\end{array}$} \\
\hline & & & & & & Sugar-free $(g / L)$ & Sum (g/L) & & $\begin{array}{l}\text { Titr. } \\
\text { (g/L) }\end{array}$ & $\begin{array}{l}\text { Vol. } \\
\text { (g/L) }\end{array}$ & $\begin{array}{c}\text { Free } \\
(\mathrm{mg} / \mathrm{L})\end{array}$ & All (mg/L) & \\
\hline 1 & Vámosújfalu & 1985 & $\mathrm{~B}$ & 365.00 & 5.53 & 94.00 & 459.00 & 3.3 & 12.12 & 0.93 & 10 & 130 & 0 \\
\hline 2 & Tolcsva & 2000 & GB & 711.60 & 1.12 & 99.60 & 811.20 & 3.26 & 13.96 & 0.39 & 8 & 24 & 46.5 \\
\hline 3 & Vámosújfalu & 2005 & B & 498.10 & 3.64 & 60.90 & 559.00 & 3.12 & 12.12 & 0.90 & 10 & 248 & 0 \\
\hline 4 & Unspecified & 2007 & B & 510.80 & 3.46 & 81.50 & 592.30 & 3.44 & 8.48 & 0.84 & 6 & 236 & 0 \\
\hline 5 & Hercegkút & 2013 & B & 509.00 & 1.95 & 69.20 & 578.20 & 2.99 & 10.50 & 0.87 & 8 & 250 & 0.00045 \\
\hline 6 & Tokaj & 2013 & B & 544.00 & 2.49 & 60.50 & 604.50 & 3.19 & 11.58 & 0.84 & 10 & 306 & 0 \\
\hline 7 & Unspecified & 2017 & GB & 538.70 & 5.11 & 79.60 & 618.30 & 3.44 & 13.60 & 1.08 & 12 & 384 & 1 \\
\hline 8 & Unspecified & 2017 & OB & 518.40 & 3.87 & 77.80 & 596.20 & 3.17 & 12.68 & 1.20 & 8 & 300 & 1 \\
\hline 9 & Mád & 2017 & $\mathrm{~B}$ & 620.10 & 2.76 & 55.60 & 675.70 & 3.32 & 12.45 & 0.05 & 6 & 18 & 6 \\
\hline 10 & Tolcsva & 2017 & B & 426.90 & 4.76 & 43.80 & 470.70 & 3.39 & 9.96 & 0.69 & 6 & 16 & 0.0004 \\
\hline 11 & Tolcsva & 2018 & $\mathrm{~T}$ & 517.90 & 3.80 & 154.70 & 672.60 & 3.52 & 10.19 & 1.08 & 12 & 210 & 0.05 \\
\hline 12 & Mád & 2018 & $\mathrm{~B}$ & 752.20 & 2.60 & 41.80 & 794.00 & 3.24 & 11.68 & 0.54 & 10 & 20 & 1 \\
\hline 13 & Tolcsva & 2019 & GB & 724.30 & 0.00 & 59.60 & 783.90 & 3.53 & 9.10 & 0.90 & 42 & 360 & 0 \\
\hline 14 & Tolcsva & 2019 & $\mathrm{C}$ & 584.00 & 4.01 & 30.10 & 614.10 & 3.4 & 11.27 & 0.93 & 6 & 16 & 0.00035 \\
\hline 15 & Unspecified & 2019 & $\mathrm{~T}$ & 729.30 & 0.00 & 50.40 & 779.70 & 3.28 & 12.64 & 0.90 & 42 & 340 & 0.00005 \\
\hline 16 & Hercegkút & 2019 & $\mathrm{~T}$ & 620.10 & 1.68 & 46.00 & 666.10 & 3.71 & 9.56 & 0.78 & 6 & 30 & 102 \\
\hline 18 & Tarcal & 2017 & GB & 740.00 & 0.39 & 34.30 & 774.30 & 3.48 & 9.94 & 0.50 & 8 & 16 & 3 \\
\hline 19 & Tarcal & 2019 & GB & 645.50 & 3.21 & 27.90 & 673.40 & 3.25 & 11.64 & 0.00 & n.d. & n.d. & 16 \\
\hline 20 & Mád & 2019 & GB & 731.90 & 2.85 & 9.10 & 741.00 & 3.59 & 8.07 & 0.00 & n.d. & n.d. & 60 \\
\hline 21 & Bodrogolaszi & 2013 & $\mathrm{~B}$ & 533.70 & 3.24 & 90.30 & 624.00 & 3.42 & 9.37 & 0.35 & n.d. & n.d. & 0.00012 \\
\hline 22 & Bodrogolaszi & 2016 & GB & 716.60 & 2.97 & 45.20 & 761.80 & 3.26 & 22.14 & 0.00 & n.d. & n.d. & 0.00052 \\
\hline 23 & Tolcsva & 2016 & $\mathrm{~T}$ & 493.00 & 4.15 & 141.40 & 634.40 & 3.3 & 19.98 & 0.53 & n.d. & n.d. & 0 \\
\hline 24 & Bodrogolaszi & 2017 & GB & 655.60 & 3.01 & 33.40 & 689.00 & 3.74 & 10.92 & 0.05 & n.d. & n.d. & 40 \\
\hline 25 & Bodrogolaszi & 2017 & $\mathrm{~T}$ & 574.30 & 3.47 & 71.80 & 646.10 & 3.74 & 12.63 & 0.47 & n.d. & n.d. & 0.5 \\
\hline 26 & Mixed & 2017 & $\mathrm{~T}$ & 681.10 & 2.97 & 49.50 & 730.60 & 3.32 & 16.22 & 0.00 & n.d. & n.d. & 0.00025 \\
\hline 27 & Bodrogolaszi & 2019 & $\mathrm{~T}$ & 609.90 & 3.00 & 76.80 & 686.70 & 3.57 & 13.43 & 0.00 & n.d. & n.d. & 22.3 \\
\hline 28 & Mád & 2013 & GB & 543.80 & 3.19 & 81.20 & 625.00 & 3.51 & 10.63 & 0.40 & n.d. & n.d. & 12 \\
\hline
\end{tabular}

${ }^{1}$ B: bottle, C: ceramic amphora, GB: glass balloon, OB: oak barrel, T: stainless steel tank; ${ }^{2}$ n.d.: not determined; ${ }^{3}$ CFU: colony-forming unit (viable cell). 


\subsection{Yeast Isolation and Phenotypic Categorisation}

To obtain individual yeast colonies, loopful volumes of the Essence samples were streaked on YEA2 and YEA35 plates. To minimise the selection bias, the media were not supplemented with agents inhibiting the growth of non-yeast microorganisms or differentiating the types of yeasts. After 7 days of incubation at $25^{\circ} \mathrm{C}, 50$ to 200 colonies were randomly isolated from the plates to obtain collections of pure isolates (single-cell clones) reflecting the population structures of the yeast biota of the wines. From samples containing low numbers of viable yeasts, 10-30 $\mu \mathrm{L}$ aliquots were spread on both types of plates, either directly or from pellets obtained by centrifugation of $100 \mathrm{~mL}$ samples. The isolates were maintained on YEA2 and YEA35 plates, stored at $5{ }^{\circ} \mathrm{C}$ and reinoculated onto fresh plates every second month.

The isolates were grouped by examining their growth morphology and the results of physiological taxonomic tests. Growth morphology (colour, surface ornamentation, production of pigmented halo in the medium) was examined by streaking the isolates on YEA2 plates and incubating at room temperature. The ability of the isolates to assimilate eight compounds (saccharose, galactose, raffinose, mannitol, maltose, cellobiose, glycerol, acetic acid) as carbon sources and two compounds (lysine and potassium nitrate) as nitrogen sources and to grow at $37^{\circ} \mathrm{C}$ and on vitamin-free medium SMA plates was tested by replica-plating, as described previously [42]. In both examinations, we encountered the problem that certain isolates were phenotypically unstable. From the cultures of these isolates, we re-isolated single-cell clones. The re-isolation did not stabilise the variable phenotypic traits, indicating that these isolates were prone to segregation.

\subsection{Molecular Taxonomy}

For taxonomic identification of the isolates, total genomic DNA was extracted from overnight cultures grown in YEL and used for the amplification of the D1/D2 domains of the 26S rRNA genes with the primers NL-1 and NL-4, as described previously [24]. The resultant amplicons were purified with a Gel/PCR DNA Fragments Extraction Kit (Geneaid Biotech Ltd.), sequenced with the same primers (Microsynth AG, Balgach, Switzerland) and the sequences were used to determine the taxonomic positions of the isolates in two steps. First, similar sequences were identified in the INDSC (International Nucleotide Sequence Database Collaboration) databases using the MEGABLAST-querying service of NCBI (https://blast.ncbi.nlm.nih.gov/Blast.cgi). In the second step, the sequences of the isolates were compared via pairwise Blast alignment (using the blast2seq algorithm available at $\mathrm{NCBI}$ ) with the D1/D2 sequences of the type strains of the species whose strains were found to be most similar in the MEGABLAST search. Sectors of segregating colonies of certain isolates were also subjected to D1/D2 analysis to verify their taxonomic identity.

\subsection{Electrophoretic Karyotyping and Microsatellite-Primed PCR (MSP-PCR) Fingerprinting}

Chromosomal DNA was prepared from the cells of overnight YEL cultures in agarose plugs, as described by Nguyen et al. [60] for Saccharomyces. The plugs were washed in TE (Tris/EDTA) and inserted into wells of 1.1\% agarose (chromosomal grade, BioRad, Hercules, California, USA) gel prepared in a $0.5 \times$ TBE (Tris/Borate/EDTA) buffer. The chromosome-sized DNA molecules were separated using pulse-field electrophoresis in $0.5 \times$ TBE with a CHEF-Mapper apparatus (Bio-Rad). The running parameters were as follows: ramping for $300 \mathrm{~s}$ over $48 \mathrm{~h}$ and ramping for $600 \mathrm{~s}$ over $48 \mathrm{~h}$ at $3 \mathrm{~V} / \mathrm{cm}$ in a TBE $0.5 \times$ buffer at $14{ }^{\circ} \mathrm{C}$. Gels were removed from the tray, stained in an ethidium bromide bath $(0.5 \mathrm{mg} / 100 \mathrm{~mL})$ and destained in sterile water. For MSP-PCR fingerprinting, genomic DNA was extracted from overnight YEL cultures. The PCR reaction was carried out with the microsatellite oligonucleotide primer $(\mathrm{GAC})_{5}$, as described by Baleiras-Couto et al. [61]. Z. rouxii CBS $732^{\mathrm{T}}$ was used as the reference strain in both procedures. 


\subsection{Extraction and Restriction Fragment Length Polymorphism (RFLP) Analysis of Mitochondrial DNA}

Mitochondrial DNA was extracted from cells of two-day YEL cultures according to Nguyen et al. [60] for Saccharomyces. A total of $10 \mu \mathrm{L}$ of mtDNA was digested with the restriction endonuclease $\mathrm{HaeIII}$ in a final volume of $20 \mu \mathrm{L}$, and the fragments were separated via electrophoresis in $1.2 \%$ agarose and $0.5 \times$ TBE. The band size was determined using the PyElph1.4 software for gel image analysis [62]. The reference strain was Z. rouxii CBS $732^{\mathrm{T}}$.

\subsection{Cluster Analysis of Molecular Patterns}

From the karyotype, MSP-PCR and mtDNA-RFLP pattern binary matrices (1: band is present, 0 : band is absent) were constructed and used for the distance calculation with the Dice coefficient [63]. The distance matrices were then analysed with the average-linkage hierarchical clustering algorithm UPGMA (Unweighted Pair Group Method with Arithmetic mean)using the service available at http:/ / genomes.urv.es/UPGMA [64]. Dendrograms were visualised with the FigTree programme (http:/ / tree.bio.ed.ac.uk).

\subsection{Phenotypic Characterisation via Drop Tests}

For drop tests on agar plates, cell suspensions (OD 0.1) were prepared in sterile water from pellets (washed once with sterile water) of centrifuged cultures of the isolates grown in YPGL for one day at $25^{\circ} \mathrm{C}$. Aliquots $(10 \mu \mathrm{L})$ of the suspensions were dropped on the test media, as described below. All tests were carried out in duplicate in two independent experiments.

2.8.1. Determination of the MIC (Minimal Inhibitory Concentration) of Glucose, Ethanol and Potassium Bisulfite $\left(\mathrm{K}_{2} \mathrm{~S}_{2} \mathrm{O}_{5}\right)$

Samples of the suspensions were dropped on the surface of YEA plates supplemented with various concentrations of glucose $(2,30,40,50,60$ and 70\%) and YEA2 plates containing various amounts of ethanol $(0,2,3,4,6,8,10,12$ and $14 \%)$ or $\mathrm{K}_{2} \mathrm{~S}_{2} \mathrm{O}_{5}(100,200,300$, 400,500 and $600 \mathrm{mg} / \mathrm{L}$ ). The plates were incubated at $25^{\circ} \mathrm{C}$, and the growth of the isolates was monitored for ten days.

\subsubsection{Growth at Various Temperatures}

To compare the effect of temperature on the growth of the isolates, samples of the suspensions were dropped on YEA2 plates, which were then incubated at 20, 25, 30 and $37^{\circ} \mathrm{C}$ for ten days.

\subsection{3. $\mathrm{H}_{2} \mathrm{~S}$ Production}

To examine the hydrogen sulphide production, samples of the suspensions were dropped on BiGGY Agar plates. The plates were incubated at $25^{\circ} \mathrm{C}$ and the changes in the colony colour were monitored for 10 days. The intensity of the colour, reflecting the intensity of $\mathrm{H}_{2} \mathrm{~S}$ production, was graded using the following visual colour scale: 1 (white), 2 (cream), 3 (light brown), 4 (brown), and 5 (dark brown).

\subsubsection{Organic Acid Production}

The intensity of the acid production was examined by culturing the isolates on Custer's chalk plates. Samples of the suspensions of the isolates were dropped on the plates and incubated at $25^{\circ} \mathrm{C}$. On the tenth day, the width of the dissolution zones around the colonies was measured.

\subsection{Examination of Biofilm Formation}

Loopful amounts of cells of cultures grown on YEA2 plates were suspended in $30 \mathrm{~mL}$ of a test medium in a $50 \mathrm{~mL}$ Erlenmeyer flask. Two types of test media were used: YEL containing $2 \%$ glucose and YEL containing 50\% glucose. The inoculated medium was incubated without agitation at room temperature for one week. If a pellicle was formed, the sample 
was taken from the surface of the medium for microscopic examination. Cells were viewed and photographed with an Olympus BX51 microscope and a DP70 digital camera.

\subsection{Growth Assay with Microplates}

Growth of the isolates in synthetic must supplemented with various amounts of sugar (fructose and glucose in 1:1 proportion) was examined in 96-well microplates. The sugar concentrations in the test media were 20,50 and 60\%. For inoculation, one-day-old precultures grown in the medium containing the same sugar concentrations were used. The precultures were centrifuged and the pellets were resuspended in the test media to obtain the initial optical density $0.1\left(\mathrm{~A}_{590}\right)$. The wells of the microplates were filled with the suspensions (200 $\mu \mathrm{L}$ in each well) in three replicates. The growth of the yeast strains in the wells at $25^{\circ} \mathrm{C}$ was monitored with a SPECTROstar Nano Microplate Reader (BMG Labtech, Offenburg, Germany) by measuring the absorbance at $A_{590}$ (no. of flashes per well and cycle were 22$)$ at regular time intervals $(10,000 \mathrm{~s})$ for 5 days. Before each cycle, the plate was shaken at $300 \mathrm{rpm}$ for $30 \mathrm{~s}$.

\subsection{Interaction and Growth Competition Tests}

The isolates were tested for interactions on a solid medium, as described previously [42]. Dense suspensions were prepared in $2 \mathrm{~mL}$ of sterile water from 7- to 10-day-old cultures grown on YEA2. Then, YEA2 plates were individually flooded with the suspension of each isolate to produce homogeneous layers (lawns) of cells on the surface of the medium. The rest of the suspension was poured off. After drying the surface of the medium, loopful amounts of other isolates were smeared on the plates in spots of $\approx 1 \mathrm{~cm}$ in diameter. The plates were then incubated at $20{ }^{\circ} \mathrm{C}$ for three weeks and examined at regular time intervals for the growth intensity of the spots and the lawn around the spots. Poor spot growth indicated that the lawn had an antagonistic effect against the spot. Clear zones and zones of poor growth around the spot indicated that the spot had an antagonistic effect against the lawn. If the spot facilitated the growth of the lawn, the latter formed a thick ring of intense growth around the spot.

The relative growth rates (competition) of the isolates in the mixed populations were examined in YEL containing 2\% glucose and in YEL supplemented with 35\% glucose. In both media, pairs of isolates representing different species were examined. For each pair, a mixed culture containing $5 \times 10^{5}$ cells $\cdot \mathrm{mL}^{-1}$ of both strains and two pure control cultures of the strains containing $10^{6}$ cells $\cdot \mathrm{mL}^{-1}$ were set up in $30 \mathrm{~mL}$ YEL. The cultures were incubated on a gyratory shaker at $20^{\circ} \mathrm{C}$. After $48 \mathrm{~h}$, the density of the cultures was determined via cell counting in a Bürker chamber and diluted aliquots were spread on plates of two types of selective SMA media from each culture. The media differed in composition such that each strain could form colonies on only one of them. For example, medium A contained trehalose and medium B contained mannitol as a carbon source in the competition test of $Z$. rouxii and P. membranifaciens. The former formed colonies on medium $\mathrm{A}$, the latter formed colonies on medium B because $\mathrm{Z}$. rouxii is mannitol ${ }^{+}$and trehalose ${ }^{-}$, whereas P. membranifaciens is mannitol ${ }^{-}$and trehalose ${ }^{+}$. Thus, the cells of each control culture could produce colonies on only one medium, whereas the cells of the mixed culture formed colonies on both. The proportion of the colony numbers produced by samples of the mixed culture spread on medium $A$ and medium $B$ showed whether the strains grew equally well when mixed (proportion $\approx 1: 1$ ) or differed in growth rate (proportion $\neq 1: 1$ ). When a Metschnikowia isolate was involved in the test, one of the media was YEA2-supplemented with $0.02 \mathrm{mg} / \mathrm{mL} \mathrm{FeCl}_{3}$, on which its cells produced maroon colonies. When the isolates differed in thermotolerance, one of the selective conditions was incubation at $35^{\circ} \mathrm{C}$. 


\section{Results}

\subsection{Sampling and Sample Characterisation}

Samples were taken from wines covering a timespan of 35 years (Table 1$)$. Six of the eight wines produced in the 2019 vintage had high CFU counts and also showed other signs (e.g., bubbles) of active fermentation. The fermentation of the Tokaj Essence is a slow process lasting for months or even years without a clear definition of completion. The rest of the 2019 vintage wines either had no culturable yeasts (wine 13) or the count of the CFUs was extremely low (wine 15). The low yeast activity in these wines could be due to excessive sulphurisation to protect the wine against the oxidation that killed the natural microflora in the early stage of fermentation (both wines had $0 \%$ alcohol). No viable yeasts were detected in four bottled wines. The sugar content ranged from 365 to $752 \mathrm{~g} \cdot \mathrm{L}^{-1}$ and the alcohol level of the wines containing culturable yeasts varied between 0.39 and 5.53\%. Low alcohol content is another characteristic feature of Essence; it rarely exceeds 7\% [47]. The $\mathrm{pH}$ did not vary significantly despite the considerable diversity in acid content.

\subsection{Isolation and Phenotypic Categorisation of Yeasts}

From the 22 wines, yeasts could be isolated as individual colonies formed on media containing either $2 \%$ (on YEA2) or 35\% (on YEA35) glucose. The latter concentration corresponded to the lowest sugar content in the examined wines. We used two sugar concentrations for yeast isolation because certain osmotolerant yeasts grow better in high sugar content (e.g., [65]). Altogether, 3209 colonies were isolated. The isolates were then divided into groups (clusters) on the basis of 10 taxonomically relevant physiological properties and the morphology of their cultures on YEA2 plates.

\subsection{Taxonomic Identification}

The taxonomic affiliations of the selected representatives of all clusters of isolates in each wine were determined using the standard D1/D2-domain-based method [66]. We opted for this method because the potential alternatives, such as ITS sequencing and MALDI-TOF, are less efficient and/or less specific. Fewer ITS sequences than D1/D2 sequences are available for yeasts in databases, and the number of available MALDI-TOF reference spectra is still limited [67]. Except for five isolates, all showed 100\% D1/D2 sequence identity with the type strains of known species (Table S1). The exceptions were isolate 8-1, which differed from the type strain of C. lactis-condensi by one substitution, and the isolates that produced maroon-red colonies. The latter had a few ambiguous nucleotides in their D1/D2 sequences, which prevented the determination of their exact taxonomic position. Nevertheless, all showed high similarity to the D1/D2 sequences of the pulcherrimin-producing Metschnikowia yeasts referred to as the pulcherrima clade [68]. The phenotypical clusters could be assigned to 13 species by sequencing the D1/D2 domains of their 99 representatives (Table S1). Interestingly, certain clusters turned out to have identical D1/D2 sequences. This finding indicated that phenotypically different conspecific clones were present in the yeast biota of certain wines (see Section 3.5).

The relative abundance of the species in the individual wines is shown in Figure 1. The most abundant yeasts were $C$. lactis-condensi and $Z$. rouxii. In four wines $(7,8,21$ and 25), all isolates belonged to C. lactis-condensi, and from two wines (22 and 28), only Z. rouxii was isolated. C. zemplinina was detected in nine wines, where in two of them (10 and 16), it was detected as the dominating but not exclusive species. The genus Zygosaccharomyces was represented by four more species (Z. bailii, Z. bisporus, Z. lentus and Z. pseudobailii) but each of them was found in one wine only. Their proportion in the population varied between 1 and $25 \%$, with the exception of Z. lentus, which formed $100 \%$ of sample 5. The rest of the species (H. osmophila, K. fluxuum, Lachancea thermotolerans, Metschnikowia pulcherrima clade sp., P. membranifaciens, C. apicola, R. mucilaginosa) occurred only sporadically. The same species in roughly identical proportions were identified on both types of media. Surprisingly, no Saccharomyces were found among the 3209 isolates. 

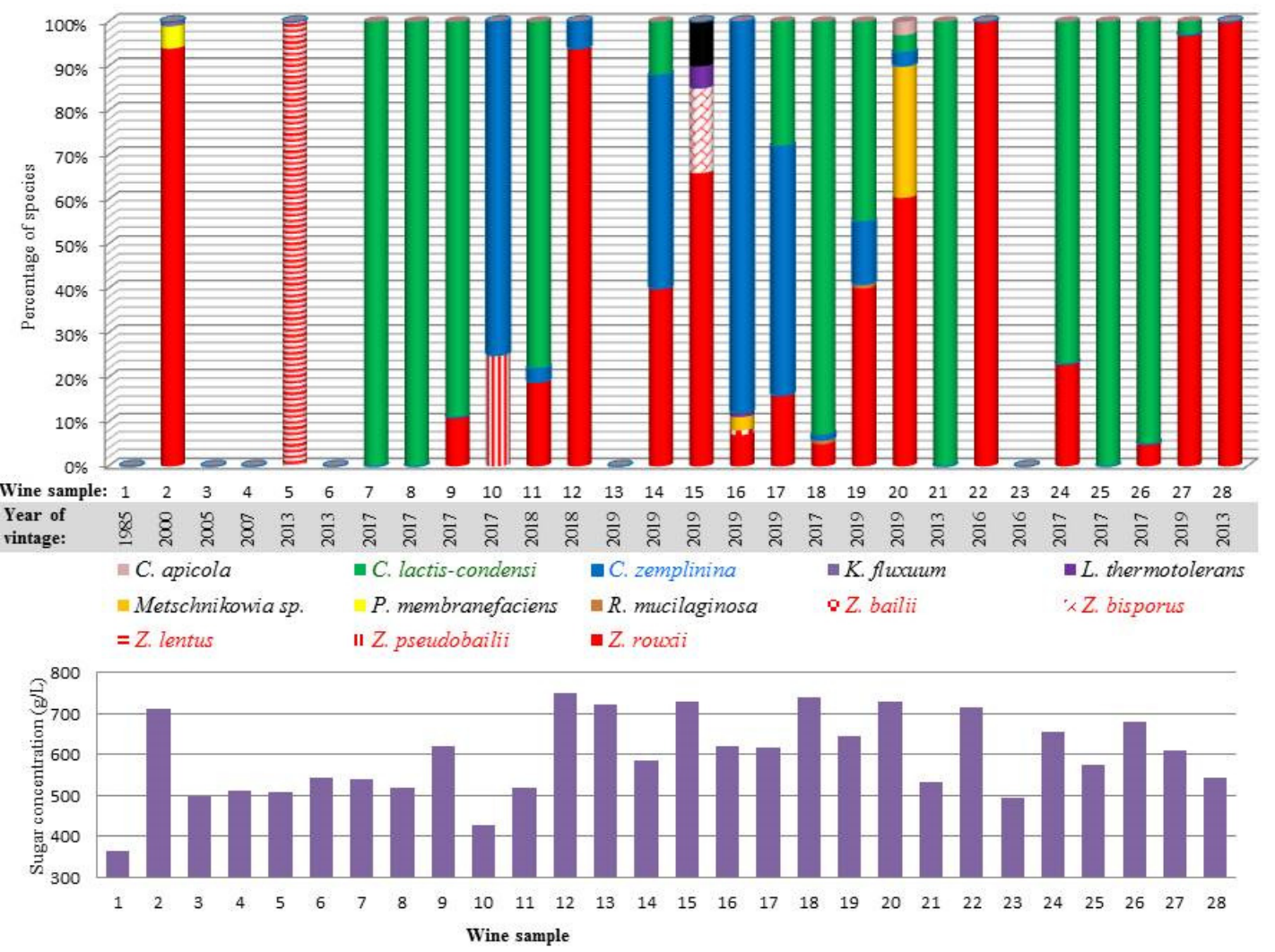

Figure 1. Composition of the yeast biota and the sugar content in the wine samples.

\subsection{Diverse Osmotolerance of the Species}

As shown above, all but one wine were dominated by Z. rouxii, C. lactis-condensi or C. zemplinina. The exception was the bottled wine 5 , from which only $Z$. lentus colonies were isolated. It is reasonable to assume that their dominance is attributable to properties that render them able to cope with the harsh environment in Essence and give them a selective advantage over (the undetected) Saccharomyces and the other yeasts found in the samples. As the most noticeable difference between the Essence juice and the normal grape juice is the very high sugar content in the Essence juice, we compared the osmotolerance of isolates representing the species. Except for the K. fluxuum, P. membranifaciens and three C. lactis-condensi isolates, all grew on the agar medium supplemented with $70 \%$ glucose but the growth of the Metschnikowia strains was very poor (Table 2).

As various yeast species with spoilage potential can form biofilms (e.g., $[69,70]$ ), we tested the isolates assigned to these species and representatives of the other species for biofilm formation by culturing them in liquid media without agitation. All K. fluxuum, P. membranifaciens, R. mucilaginosa and Metschnikowia isolates, but none of the isolates of the other species, formed pellicles (films) on the surface of the medium at both glucose concentrations ( 2 and 50\%) (Figure 2). The K. fluxuum and P. membranifaciens films consisted of firmly aggregated cells, whereas the Metschnikowia and R. mucilaginosa films were formed by loosely connected short pseudohyphae. Even gentle shaking disrupted the Metschnikowia and R. mucilaginosa films and caused a massive sinking of cells. 
Table 2. The minimal inhibitory concentrations (MICs) of glucose as determined in agar plate tests for representatives of each species.

\begin{tabular}{ccc}
\hline Isolate & Species & $\begin{array}{c}\text { MIC } \\
\text { (\% Glucose) }\end{array}$ \\
\hline $15-1$ & H. osmophila & $>70$ \\
$2-25$ & K. fluxuum & 40 \\
$15-11,16-33$, G20-16 & L. thermotolerans & $>70$ \\
$16-39,20-1$, G20-6 & M. pulcherrima clade $s p$ & $\leq 70$ \\
$2-40,2-65$ & P. membranifaciens & 60 \\
G10-1, 11-25, 12-63, 14-4, 20-18 & C. zemplinina & $>70$ \\
G8-1, 11-33 & & $>70$ \\
G9-4, & C. lactis-condensi & 60 \\
$9-1,19-1$ & & 50 \\
$16-30$ & Z. bailii & $>70$ \\
5-2, 5-43, G5-1 & Z. lentus & $>70$ \\
$10-4$ & Z. pseudobailii & $>70$ \\
All isolates & Z. rouxii & $>70$ \\
\hline
\end{tabular}
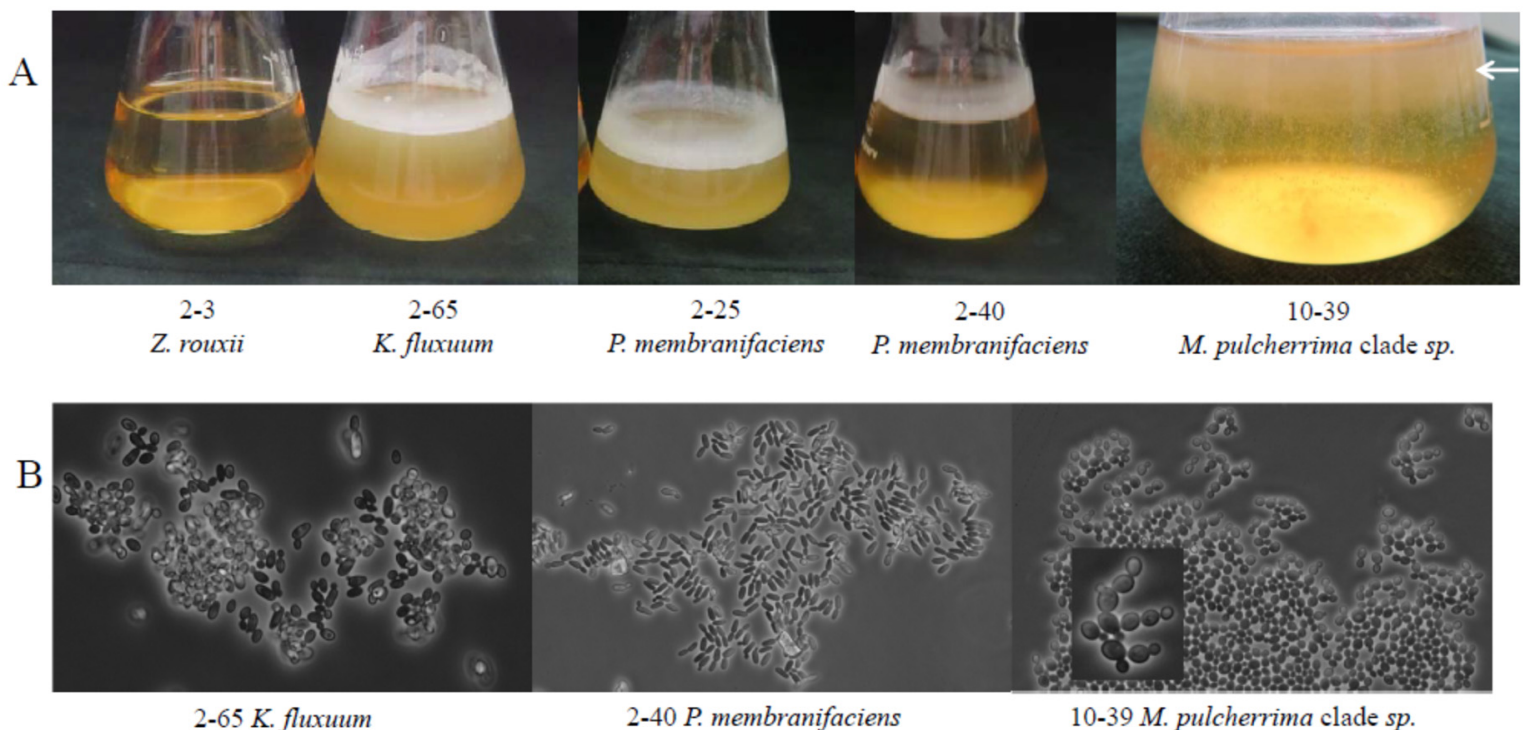

Figure 2. Surface film (pellicle) formation: (A) films on a liquid medium and (B) microscopic morphology of cells in samples taken from films. The white arrow shows descending cells/pseudohyphae after gentle shaking of the Metschnikowia culture.

The effect of the sugar concentration on the growth of selected representatives of the species was also tested in artificial must. The optical density of the microplate cultures after five days (119 h $27 \mathrm{~min}$ ) of incubation is shown in Table S2 and Figure S1. Figure 3 compares the growth of the species. All but one strain grew much better at $20 \%$ sugar than at higher sugar concentrations. The exception was C. apicola, which seemed to be slightly osmophilic. Remarkably, in these tests, the C. zemplinina isolates proved highly sensitive to 50 and $60 \%$ sugar, and the Zygosaccharomyces isolates grew much better than the strains of the other species at $20 \%$ sugar. 


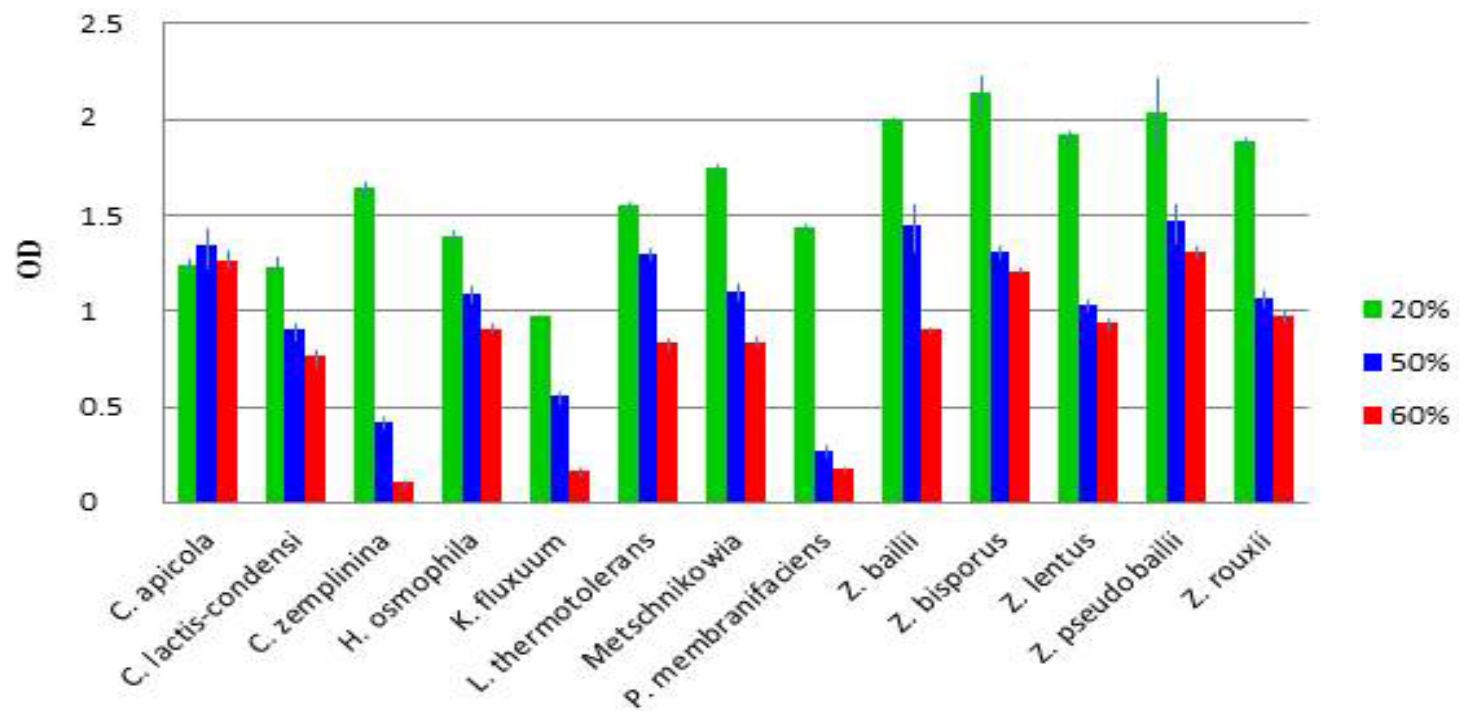

Figure 3. Microplate growth assay. The columns show the average optical density (OD) values calculated from the results shown in Table $\mathrm{S} 2$.

\subsection{Intraspecies Phenotypic Diversity}

As mentioned above, certain phenotypically different groups of isolates proved to be conspecific in the molecular taxonomic examinations. One of the variable traits was the morphology of the colonies. Figure 4 shows how diverse colony morphologies were observed among the $Z$. rouxii and C. zemplinina isolates.

A

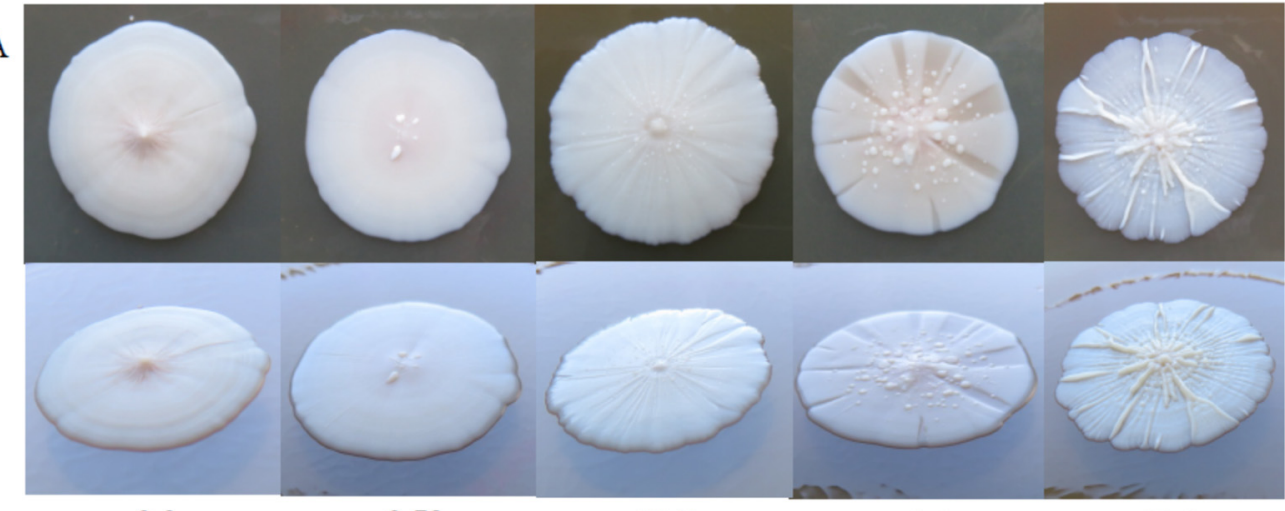

$9-3$

$9-78$

$20-7$

$2-1$

$28-1$

B

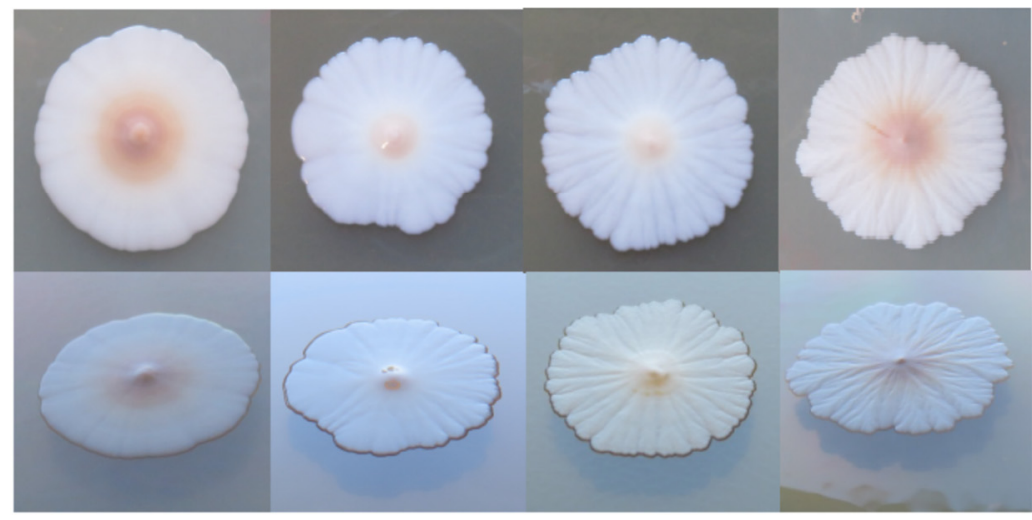

G10-1

7-1

17-1

20-18

Figure 4. Diverse colony morphologies: (A) Z. rouxii and (B) C. zemplinina. 
The Z rouxii isolates were also variable in their utilisation of maltose as a carbon source and the ability to grow at $37^{\circ} \mathrm{C}$ (Table 3). Further differences were detected in their growth intensity on media containing galactose, glycerol or mannitol as carbon sources or lysine as the nitrogen source. To further explore the diversity of the $Z$. rouxii isolates, we compared the ability of 46 isolates to grow at elevated concentrations of glucose, ethanol and $\mathrm{K}_{2} \mathrm{~S}_{2} \mathrm{O}_{5}$. All grew at 70\% glucose but the MIC (minimal inhibitory concentration) of ethanol and $\mathrm{K}_{2} \mathrm{~S}_{2} \mathrm{O}_{5}$ varied considerably $\left(10-14 \%\right.$ and $300-800 \mathrm{mg} \cdot \mathrm{L}^{-1}$, respectively). The isolates also proved diverse in their acid secretion and $\mathrm{H}_{2} \mathrm{~S}$ production.

Apart from their morphological diversity (Figure 5), the colonies of certain isolates segregated into sectors which were identical in D1/D2 sequences. Upon inoculation on fresh medium, the sectors usually retained their morphology but were prone to recurrent segregation. This phenomenon was observed among the Z. rouxii, L. thermotolerans, C. lactiscondensi, P. membranifaciens and Metschnikowia isolates.

20-2

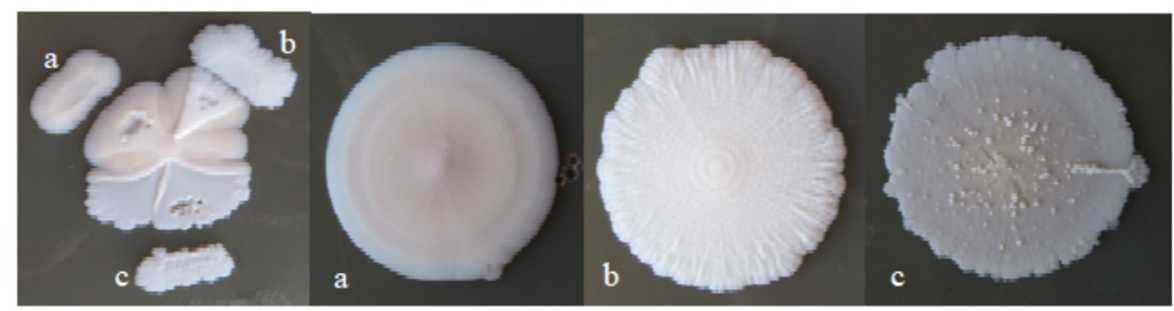

Z. rouxi

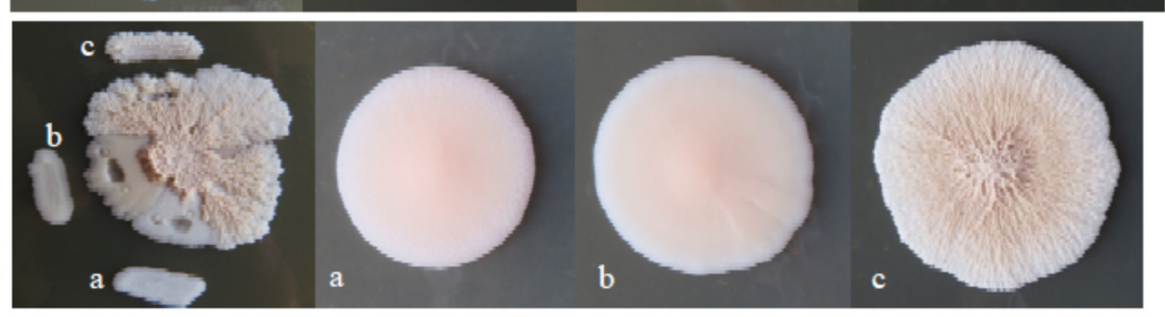

P. membranifaciens
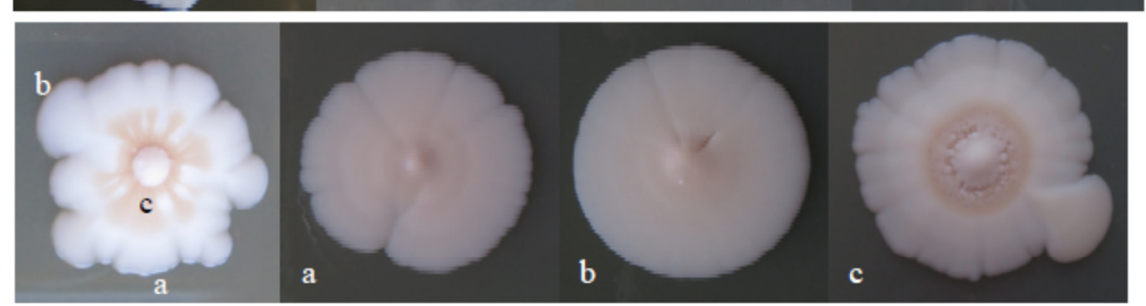

L.. thermotolerans
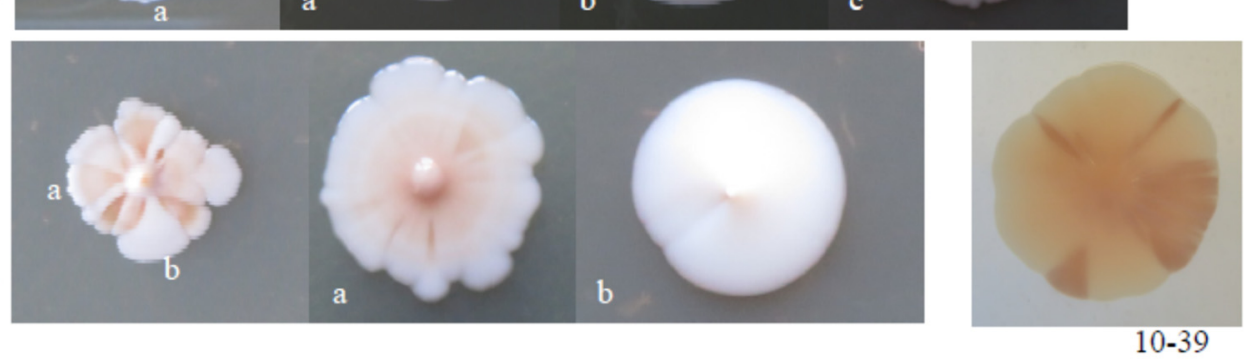

Metschnikowia

Figure 5. Segregating colonies: $(\mathbf{a}-\mathbf{c})$ sectors and the colonies formed by cells 324 of the sectors transferred on fresh agar plates. 
Table 3. Phenotypic diversity of Z. rouxii isolates.

\begin{tabular}{|c|c|c|c|c|c|c|c|c|c|c|c|c|}
\hline \multirow{2}{*}{ Isolate } & \multirow{2}{*}{$\begin{array}{c}\text { Colony } \\
\text { Morphology }\end{array}$} & \multicolumn{6}{|c|}{ Growth on/at ${ }^{1}$} & \multicolumn{3}{|c|}{ MIC } & \multirow{2}{*}{$\begin{array}{l}\text { Acid Prod } \\
(\mathrm{mm})\end{array}$} & \multirow{2}{*}{ BiGGY } \\
\hline & & Mannitol & Galactose & Glycerol & Maltose & Lysine & $37^{\circ} \mathrm{C}$ & Glucose (\%) & Ethanol (\%) & Sulphur $\left(\mathrm{mg} \cdot \mathrm{L}^{-1}\right)$ & & \\
\hline $9-3$ & Rough white & + & + & + & + & + & + & $>70$ & 14 & 300 & 3 & 3 \\
\hline $9-78$ & Dull white & + & + & + & + & + & + & $>70$ & 14 & 300 & 3 & 3 \\
\hline $9-85$ & Rough white & + & + & + & + & + & + & $>70$ & 14 & 300 & 3 & 3 \\
\hline G9-1 & Dull white & + & + & + & + & + & + & $>70$ & 14 & 300 & 3.5 & 4 \\
\hline $12-8$ & Dull white & + & + & + & + & + & + & $>70$ & 12 & 700 & 3 & 4 \\
\hline G12-1 & Dull white & + & + & + & + & + & + & $>70$ & 12 & 700 & 3.5 & 4 \\
\hline $20-2$ & Rough white & + & + & + & + & + & + & $>70$ & 14 & 700 & 2.5 & 4 \\
\hline $15-2$ & Dull white & + & + & + & $\mathrm{w}$ & + & + & $>70$ & 12 & 800 & 2.5 & 3 \\
\hline $15-5$ & Dull white & + & + & + & $\mathrm{w}$ & + & + & $>70$ & 14 & 800 & 2 & 3 \\
\hline G17-1 & Dull white & + & + & + & $\mathrm{w}$ & + & + & $>70$ & 14 & 300 & 2 & 3 \\
\hline $11-10$ & Dull white & + & + & + & - & + & + & $>70$ & 14 & 800 & 1.75 & 2 \\
\hline $12-2$ & Dull white & + & + & + & - & + & + & $>70$ & 14 & 300 & 3 & 3 \\
\hline $12-23$ & Dull white & + & + & + & - & + & + & $>70$ & 14 & 400 & 2 & 1 \\
\hline $14-2$ & Dull white & + & + & + & - & + & + & $>70$ & 14 & 300 & 3 & 4 \\
\hline $20-7$ & Rough white & + & + & + & - & + & + & $>70$ & 14 & 300 & 3 & 4 \\
\hline $27-1$ & Dull white & + & + & + & + & + & $\mathrm{w}$ & $>70$ & 14 & 700 & 3 & 3 \\
\hline G22-1 & Dull white & + & + & + & + & + & - & $>70$ & 12 & 700 & 3 & 3 \\
\hline $24-2$ & Dull white & + & + & + & + & + & - & $>70$ & 12 & 700 & 2.5 & 3 \\
\hline $12-43$ & Rough white & + & + & + & + & $\mathrm{w}$ & - & $>70$ & 14 & 300 & 3 & 3 \\
\hline $14-21 c$ & White sectored & + & + & + & $\mathrm{w}$ & + & $\mathrm{w}$ & $>70$ & 12 & 700 & 2 & 4 \\
\hline $17-14$ & Dull white & + & + & + & $\mathrm{w}$ & + & $\mathrm{w}$ & $>70$ & 12 & 800 & 1.5 & 3 \\
\hline G16-36 & Rough white & + & + & + & $\mathrm{w}$ & + & - & $>70$ & 14 & 300 & 3 & 3 \\
\hline $17-62$ & Dull white & + & + & + & $\mathrm{w}$ & + & - & $>70$ & 14 & 800 & 2 & 2 \\
\hline $27-83$ & Rough white & + & + & + & $\mathrm{w}$ & + & - & $>70$ & 10 & 400 & 3.5 & 4 \\
\hline G21-21 & Dull white & + & + & + & - & + & $\mathrm{w}$ & $>70$ & 14 & 700 & 3.5 & 3 \\
\hline $2-1$ & Dull white & + & + & + & - & + & - & $>70$ & 14 & 700 & 3.5 & 3 \\
\hline $2-3$ & Dull white & + & + & + & - & + & - & $>70$ & 14 & 700 & 3.5 & 3 \\
\hline $2-42$ & Dull white & + & + & + & - & + & - & $>70$ & 14 & 600 & 3 & 3 \\
\hline $\mathrm{G} 2-1$ & Dull white & + & + & + & - & + & - & $>70$ & 14 & 600 & 3 & 3 \\
\hline $14-21 a$ & Dull white & + & + & + & - & + & - & $>70$ & 13 & 300 & 3 & 4 \\
\hline $14-53$ & Dull white & + & + & + & - & + & - & $>70$ & 12 & 300 & 3 & 4 \\
\hline
\end{tabular}


Table 3. Cont.

\begin{tabular}{|c|c|c|c|c|c|c|c|c|c|c|c|c|}
\hline \multirow{2}{*}{ Isolate } & \multirow{2}{*}{$\begin{array}{c}\text { Colony } \\
\text { Morphology }\end{array}$} & \multicolumn{6}{|c|}{ Growth on/at ${ }^{1}$} & \multicolumn{3}{|c|}{ MIC } & \multirow{2}{*}{$\begin{array}{l}\text { Acid Prod } \\
(\mathrm{mm})\end{array}$} & \multirow{2}{*}{ BiGGY } \\
\hline & & Mannitol & Galactose & Glycerol & Maltose & Lysine & $37^{\circ} \mathrm{C}$ & Glucose (\%) & Ethanol (\%) & Sulphur $\left(\mathrm{mg} \cdot \mathrm{L}^{-1}\right)$ & & \\
\hline G14-1 & Dull white & + & + & + & - & + & - & $>70$ & 12 & 300 & 3 & 4 \\
\hline G20-1 & Dull white & + & + & + & - & + & - & $>70$ & 12 & 400 & 3.5 & 4 \\
\hline G20-56 & Rough white & + & + & + & - & + & - & $>70$ & 12 & 400 & 3.5 & 4 \\
\hline G24-10a & Dull white & + & + & + & - & + & - & $>70$ & 12 & 600 & 3 & 3 \\
\hline G27-1 & Rough white & + & + & + & - & + & - & $>70$ & 14 & 700 & 3 & 3 \\
\hline $12-30$ & Dull white & + & + & + & - & $\mathrm{w}$ & + & $>70$ & 14 & 400 & 2 & 1 \\
\hline $19-6$ & Dull white & + & + & + & - & $\mathrm{w}$ & $\mathrm{w}$ & $>70$ & 12 & 800 & 3 & 1 \\
\hline G19-1 & Dull white & + & + & + & - & $\mathrm{w}$ & - & $>70$ & 14 & 800 & 2 & 1 \\
\hline $28-1$ & Dull white & $\mathrm{w}$ & w & w & $\mathrm{w}$ & $\mathrm{w}$ & - & $>70$ & 12 & 400 & 2 & 1 \\
\hline $28-5$ & Dull white & $\mathrm{w}$ & $\mathrm{w}$ & $\mathrm{W}$ & $\mathrm{w}$ & $\mathrm{w}$ & - & $>70$ & 12 & 400 & 2.5 & 1 \\
\hline $28-58$ & Dull white & $\mathrm{w}$ & $\mathrm{w}$ & $\mathrm{w}$ & $\mathrm{w}$ & $\mathrm{w}$ & - & $>70$ & 12 & 600 & 1 & 1 \\
\hline G28-1 & Dull white & $\mathrm{w}$ & $\mathrm{w}$ & $\mathrm{w}$ & $\mathrm{w}$ & $\mathrm{w}$ & - & $>70$ & 12 & 600 & 1 & 1 \\
\hline
\end{tabular}




\subsection{Intraspecies Molecular Diversity in Z. rouxii}

Next, we asked whether differences can also be found in the genomes of the isolates. Towards this end, we compared the karyotypes, the MSP-PCR patterns of the nuclear genomes and the RFLP patterns of the mitochondrial genomes of the $Z$. rouxii isolates. The isolates proved highly diverse in all tests. The highest diversity was detected with MSPPCR (Figure 6). The total number of MSP-PCR patterns was 26, of which, 19 were unique. Seven patterns were shared by two to five isolates. The number of the mtDNA patterns was 19 (Figure S2) and 7 karyotypes (Figure S3) could be distinguished. A comparison of the dendrograms derived from the banding patterns revealed low similarity in their topology (Figure 6). Isolates showing identical MSP-PCR patterns were grouped in different clusters on the karyotype and mtDNA dendrograms. For example, the members of the largest group of identical MSP-PCR patterns had three different karyotypes and two different mtDNA patterns. The type strain of $Z$. rouxii $\left(\mathrm{CBS} 732^{\mathrm{T}}\right)$ shared its MSP-PCR pattern with one of the isolates but had a unique mtDNA pattern and a unique karyotype. Strains isolated from the same wine rarely had identical MSP-PCR and mtDNA RFLP patterns, indicating that different clones constituted the $\mathrm{Z}$. rouxii population. For example, the 8 strains isolated from wine 12 had 5 karyotypes, 5 MSP-PCR and 5 mtDNA-RFLP patterns, and the pattern identity from one test did not always correlate with the identity from the other tests.

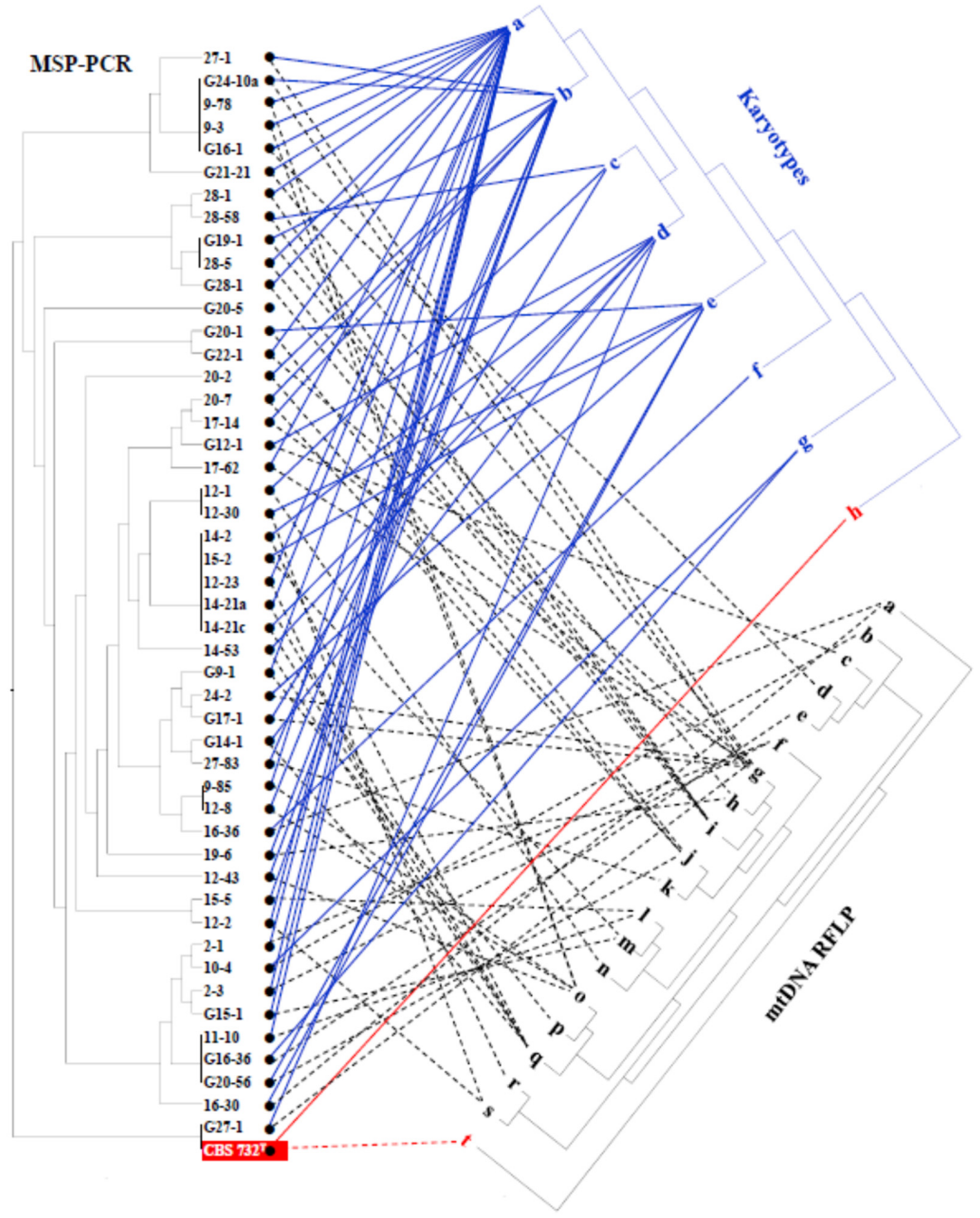

Figure 6. Molecular diversity of the Z. rouxii isolates. Comparison of the positions of the isolates on microsatellite-primed (MSP)-PCR, karyotype, and mtDNA restriction fragment length polymorphism (RFLP) dendrograms. 


\subsection{Interactions and Competitions of Isolates}

In mixed populations, microorganisms can interact and their interactions then shape the population kinetics. To find out whether the yeasts of the Essence wines can interact in any way, we tested representative isolates to see whether they affected each other's growth on agar plates (Table 4, Figure 7). The Lachancea colonies inoculated on tester lawns reduced the growth of the lawns (turbid inhibition zones) of almost all other isolates. The exception was one of the P. membranifaciens strains, whose lawn was not affected by one of the L. thermotolerans isolates. Interestingly, when the Lachancea isolates were used as lawns, they formed halos of thicker growth around the Pichia and Zygosaccharomyces colonies, presumably due to cross-feeding by nutrients or growth factors released by the colonies. Clear inhibition zones (the lawn did not grow within the zone) were rarely observed and were narrow. Remarkably, the $Z$. rouxii isolates reduced the growth of the lawns of the H. osmophila, K. fluxuum and P. membranifaciens isolates, as well as one of the C. lactiscondensi isolates. When pairs of isolates were cultured in liquid media, their proportion changed during the $48 \mathrm{~h}$ long test period (Table 5). Only combinations were examined in which the cells of isolates could be enumerated by different colony-forming abilities in different conditions (on media supplemented with different nutrients and by incubation at different temperatures). At $2 \%$ sugar, almost all tested isolates grew faster than $Z$. rouxii. Five non-Zygosaccharomyces isolates drastically overgrew the Z. rouxii isolate. At $30 \%$ sugar, the proportions changed in favour of $Z$. rouxii in certain combinations. The largest changes were detected in the mixed cultures of $Z$. rouxii with $C$. zemplinina and $C$. lactis-condensi: at $2 \%$ glucose, the mixed cultures contained more Candida cells, while at $30 \%$ glucose, the number of $Z$. rouxii cells was higher. Supplementation of the medium with $30 \%$ glucose caused 18-fold (compared to C. lactis-condensi) and 60-fold (compared to C. zemplinina) increases in the relative abundance of the $Z$. rouxii cells.

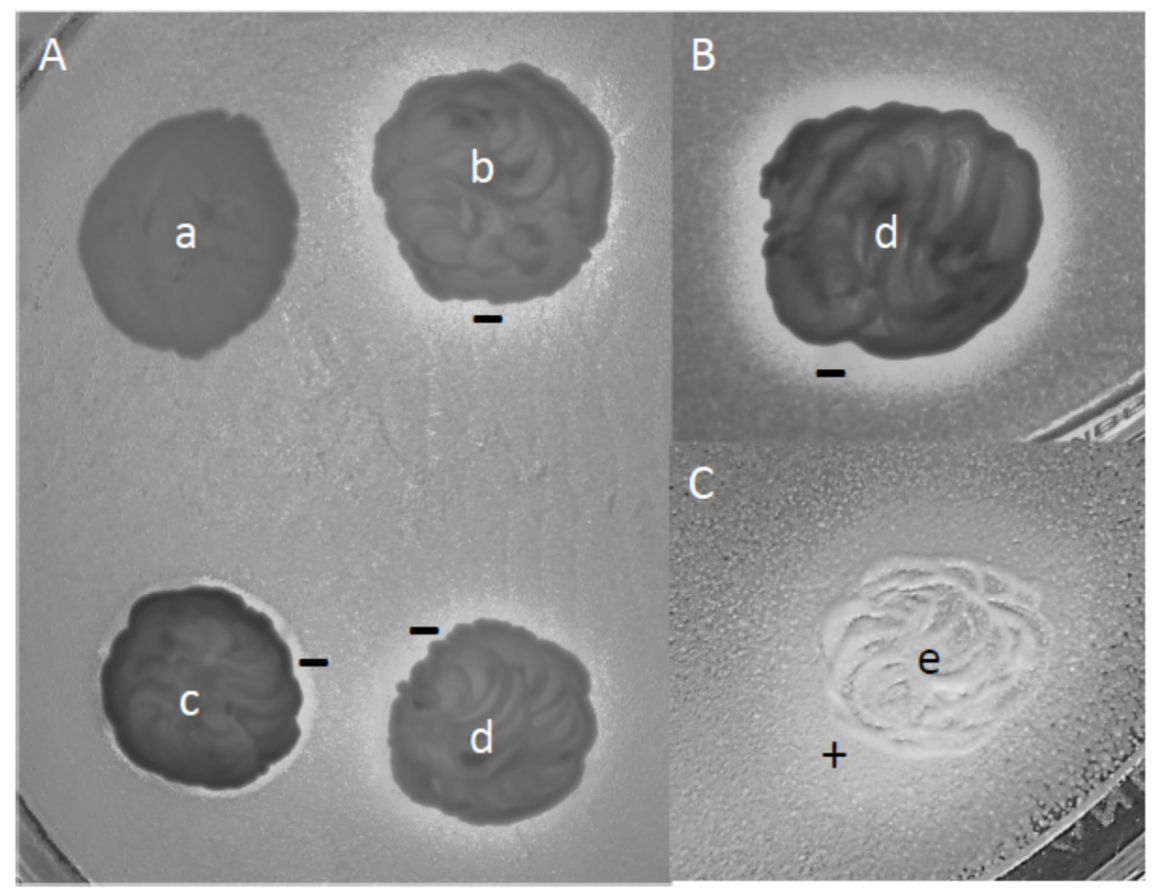

Figure 7. Interactions of isolates on an agar medium. Lawn: 20-2 Z. rouxii (A), G8-1 C. lactiscondensi (B) and 16-33 L. thermotolerans (C). Colonies: 15-1 H. osmophila (a), 16-33 L. thermotolerans (b), 20-1 Metschnikowia sp. (c), 15-11 L. thermotolerans (d) and Z. pseudobailii (e). -: reduced growth (antagonism). +: increased growth (crossfeeding). 
Table 4. Interactions of isolates on agar plates. Results of two experiments.

\begin{tabular}{|c|c|c|c|c|c|c|c|c|c|c|c|c|c|c|c|c|c|c|}
\hline \multirow{2}{*}{\multicolumn{2}{|c|}{ Colony }} & \multicolumn{17}{|c|}{ Width of Inhibition Zones $(\mathrm{mm})$ in the Lawn of } \\
\hline & & G8-1 & G11-4 & 11-25 & $17-1$ & $15-1$ & $2-25$ & $15-11$ & $16-33$ & $20-1$ & 16-39 & $2-65$ & $2-40$ & $2-3$ & $20-2$ & $16-30$ & $5-2$ & $10-4$ \\
\hline Isolate & Species & 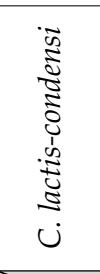 & 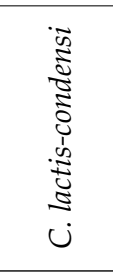 & 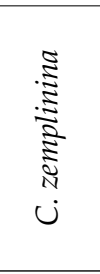 & 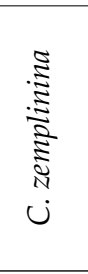 & 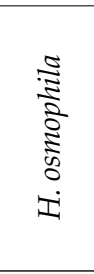 & 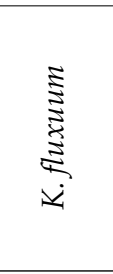 & 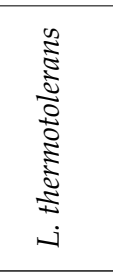 & 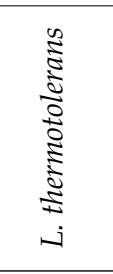 & 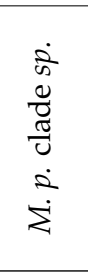 & $\begin{array}{l}\frac{\dot{0}}{\text { s }} \\
\frac{0}{0} \\
\frac{\pi}{U} \\
\dot{2} \\
\dot{\Sigma}\end{array}$ & 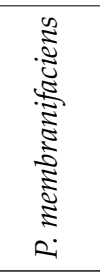 & 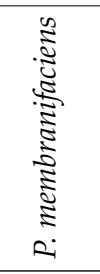 & 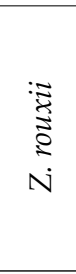 & 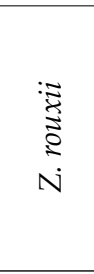 & $\begin{array}{l}: \bar{\Xi} \\
\stackrel{\Xi}{\Xi} \\
N \\
N\end{array}$ & $\frac{\underset{N}{\frac{N}{2}}}{\frac{a}{2}}$ & 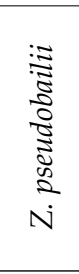 \\
\hline G8-1 & C. lactis-condensi & & - & - & - & - & - & - & - & - & - & - & - & - & - & - & - & - \\
\hline G11-4 & C. lactis-condensi & - & & - & - & - & - & - & - & - & - & - & - & - & - & - & - & - \\
\hline $11-25$ & C. zemplinina & - & 2,2 & & - & 3,3 & - & 2,2 & - & - & - & - & - & - & - & - & - & - \\
\hline $17-1$ & C. zemplinina & - & - & - & & 3,2 & crossf & 2,2 & - & - & - & - & - & - & - & - & - & - \\
\hline $15-1$ & H. osmophila & - & - & - & - & & - & - & - & - & - & - & - & - & - & - & - & - \\
\hline $2-25$ & K. fluxuum & - & - & - & - & - & & crossf & crossf & - & - & - & - & - & - & - & - & - \\
\hline $16-33$ & L. thermotolerans & 1,1 & 2,2 & 2,2 & 2,1 & 1,1 & 2,2 & 2,2 & $><$ & 3,0 & 2,2 & - & - & 1,1 & 2,2 & 2,1 & 1,1 & 1,1 \\
\hline $20-1$ & M. pulcherrima clade $s p$. & 1,0 & 1,1 & - & 1,0 & - & crossf & crossf & - & & - & - & - & - & 1,1 & - & - & - \\
\hline $16-39$ & M. pulcherrima clade $s p$. & - & 1,1 & - & 1,1 & - & - & - & crossf & - & $>$ & $0.5,1$ & $0.5,1$ & - & 1,0 & - & - & - \\
\hline $2-65$ & P. membranifaciens & - & 1,0 & - & - & - & - & - & crossf & - & - & & - & - & - & - & - & - \\
\hline $2-3$ & Z. rouxii & - & 1,0 & - & - & 1,0 & 1,0 & - & - & - & - & 1,1 & $1,0.5$ & & - & - & - & - \\
\hline $20-2$ & Z. rouxii & - & 3,3 & - & - & - & 1,0 & crossf & crossf & - & - & 1,1 & 1,1 & - & & - & - & - \\
\hline $16-30$ & Z. bailii & - & 1,0 & - & - & - & - & crossf & crossf & - & - & $0.5,0$ & - & - & - & & - & - \\
\hline $5-2$ & Z. lentus & - & 1,0 & - & - & - & - & crossf & crossf & - & - & 1,0 & $0.5,0$ & - & - & - & & - \\
\hline $10-4$ & Z. pseudobailii & - & - & - & - & - & - & crossf & crossf & - & - & - & - & - & - & - & - & \\
\hline
\end{tabular}


Table 5. Growth in mixed cultures.

\begin{tabular}{|c|c|c|c|}
\hline \multicolumn{2}{|c|}{ Mixed Cultures } & \multicolumn{2}{|c|}{ Proportion of Isolates after $48 \mathrm{~h}$ of Incubation a } \\
\hline Isolates & Species Combination & $2 \%$ Glucose & $30 \%$ Glucose \\
\hline $2-3+10-4$ & Z. rouxii + Z. pseudobailii & $1: 1.03$ & $1: 8$ \\
\hline $2-3+16-30$ & Z. rouxii + Z. bailii & n.d. & 1.18:1 \\
\hline $2-3+\mathrm{G} 11-4$ & Z. rouxii + C. lactis-condensi & $1: 1.19$ & $15.25: 1$ \\
\hline $2-3+11-25$ & Z. rouxii + C. zemplinina & $1: 24$ & 2.4:1 \\
\hline $11-25+\mathrm{G} 11-4$ & $\begin{array}{l}\text { C. zemplinina }+C . \\
\text { lactis-condensi }\end{array}$ & $1: 1.13$ & $1: 5.4$ \\
\hline $2-3+15-1$ & Z. rouxii + H osmophila & $1: 75$ & $1: 14.3$ \\
\hline $2-3+15-11$ & Z. rouxii + L. thermotolerans & $1:>57$ & n.d \\
\hline $2-3+16-39$ & Z. rouxii + Metschnikowia & $1:>84$ & n.d. \\
\hline $2-3+2-65$ & Z. rouxii + P. membranifaciens & $1:>28$ & n.d. \\
\hline
\end{tabular}

n.d.: not determined.

\section{Discussion}

Yeast isolation was attempted from samples taken from 28 Tokaj Essence wines ranging in age from half a year to 35 years and in sugar content from 365 to $752 \mathrm{~g} \cdot \mathrm{L}^{-1}$. Viable yeasts were found in 22 wines, but the number of colony-forming units showed a high diversity. The wines made from the juice of nobly rotten grapes harvested during last year's (2019) vintage had high numbers of culturable yeast cells, indicating that they were in the phase of active fermentation despite the fact that 5 to 6 months had passed since the harvest. The only exception was a wine that was heavily treated with sulphur dioxide against oxidation. The older wines were heterogeneous in viable yeast content. As the fermentation of the Tokaj Essence is a slow process lasting for months or even years without a clear definition of completion (alcohol content, residual sugar), it is unclear whether the older wines having higher numbers of CFUs were still in the primary fermentation stage or in secondary (re)fermentation. All but one of the bottled wines contained no viable yeast cells. From the 22 wines, 3209 yeast colonies were isolated via a random selection. To avoid immense sequencing, the isolates were first divided into phenotypic categories and then only representatives of the categories were sequenced. This strategy previously proved efficient in investigating yeast communities of botrytised grapes [42]. The analysis of the D1/D2 sequences amplified from 99 isolates identified 13 species that are all known to cause microbial spoilage in high-sugar beverages and food products (e.g., [6,33,71-74]) and occur in fermenting and aging wines of high sugar contents (e.g., [6,10,75-77]).

\subsection{Dominant and Associated Yeasts}

The yeast populations of the wines were dominated by two groups of related yeasts. Zygosaccharomyces species were found in 18 out of the 22 wines containing culturable yeasts, and strains of the closely related C. lactis-condensi and C. zemplinina were detected in 17 wines. The genus Zygosaccharomyces consists of fifteen species (NCBI Taxonomy, Oct, 2020), of which Z. bailii, Z. bisporus, Z. lentus, Z. pseudobailii and Z. rouxii were represented among the isolates. C. lactis-condensi and C. zemplinina are almost indistinguishable by conventional taxonomic tests and were recently transferred to Starmerella, a rapidly expanding genus that harbours yeast species that occur frequently on flowers and flower-visiting insects [51].

Z. rouxii was found in 16 Essence wines, in two as the only species and in five as the dominating yeast. The other Zygosaccharomyces species were much less abundant; each was only found in one wine, with each found in a different wine. From these results, it can be concluded that although five Zygosaccharomyces species were detected in the Essence wines, only Z. rouxii appeared to play a significant role in the vinification process. Its presence and high abundance in the majority of the examined wines is somewhat 
surprising because it is a rare component of the grape microflora in the Tokaj region [72], and its relative, $Z$. bailii is present much more frequently in high-sugar wines. The latter was previously detected in aging Sauternes wines [75], vino cotto [6] and in a sweet Tokaj wine [29], but in this study, it was only found as a minor component of the yeast population in a fermenting Essence from last year's vintage. This yeast is thought to get into the wine from the grapes, particularly from berries damaged by rotting [9]. This can also be the case in the Essence wine because a previous study detected this species in botrytised berries in the Tokaj region [42]. Z. bailii is one of the most common spoilage microorganisms of high-sugar food and wine (for a recent review, see [73]), but it has also been reported to be beneficial for vinification [78-82]. Thus, its presence in Essence wine is not necessarily negative. The closely related Z. pseudobailii (differing from Z. bailii by only one substitution in the D1/D2 sequence) was found in a bottled wine together with three non-Zygosaccharomyces species. The examined bottle had a very low number of CFUs and did not show any sign of fermentation. This species has a chimeric (admixed) genome that is assumed to have evolved from the hybridisation of Z. bailii and an unidentified species of the genus [22]. Z. bisporus was also found in an Essence wine from last year's vintage but that wine had a very low number of culturable yeasts and did not show signs of fermentation. According to the information received from the winery, it was heavily sulphurised in order to prevent oxidation. The low yeast activity could be attributed to this treatment. Z. bisporus is closely related to Z. bailii and Z. pseudobailii [83,84]. It was described as spoilage yeast with intermediate features between Z. rouxii and Z. bailii [71,72] and has been isolated from both healthy grapes [54] and rotten grapes [85]. From one of the bottled Essence wines, only Z. lentus was isolated. This recently described species is characterised by a stress tolerance similar to that of Z. bailii but it grows slowly at low temperatures [86]. This property might account for its low abundance in the Essence wines, which are fermented and stored at low temperatures. The sporadic occurrence of the non-rouxii Zygosaccharomyces species in the Essence wines and their low abundance indicate that they only play minor roles (if any) in fermentation, but may affect the development of the sensorial properties of the wine during aging.

C. lactis-condensi was the exclusive or the dominating species in 10 wines. In terms of the number of dominated wines, C./S. lactis-condensi seems to be the best-fitted yeast for propagation in and fermentation of the Essence wines. However, apart from being sporadically detected in spontaneous wine fermentation [23,87], little is known about its oenological properties. C. zemplinina constituted the majority in four wines. Both C. lactiscondensi and C. zemplinina were previously detected in sweet Tokaj wines, including Essencetype wines $[23,24,49,88-90]$. The latter has been found in many wine-growing regions of the world usually in botrytised $[10,44,90]$ and sweet wines (e.g., [77,91-93]) and turned out to have a beneficial effect on wine quality in fermentations inoculated with mixed starters (for a review, see [94]). Because of these properties, it can be assumed to play a positive role in the fermentation of the Essence wines. Its close relative, $C$ apicola (recently renamed to S. apicola [51]), was found as a minor component of the yeast biota in the wine populated by the most diverse yeast community (five species). This species has also been found in high-sugar substrates, including wines (e.g., [6,33,74]).

Low percentages of the yeasts isolated from two wines in the stage of active fermentation (last year's vintage, high density of CFUs) showed taxonomic affiliation with the pulcherrima clade of Metschnikowia, but could not be assigned to any species because their D1/D2 sequences contained ambiguous nucleotides at certain positions. Di- and polymorphic nucleotides often occur in the D1/D2 sequences of pulcherrimin-producing Metschnikowia isolates when amplified directly from genomic DNA [68]. This phenomenon is attributable to inefficient homogenisation of the rDNA repeats. The analysis of the genome sequences of certain strains of the pulcherrima clade revealed that their rDNA is fragmented and thus evolves via the birth-and-death mechanism rather than via homogenisation, which is unusual in yeasts [68]. Yeasts belonging to this clade are ubiquitous on/in fruits, beverages and fruit-based food products (e.g., [85,95]) and were also found in botry- 
tised grapes from the Tokaj region [42,96]. As the fermentation power of Metschnikowia is lower than that observed for other non-Saccharomyces species [15], the strains found in the Essence wines are not likely to significantly contribute to the fermentation process but they may modulate the composition of the wine. Strains of the pulcherrima clade have been found to affect wine quality, both positively and negatively (for recent reviews, see $[15,85]$ ).

The rest of the species were only found in very low numbers. A few colonies formed on the plates inoculated with samples of a 10-year-old wine dominated by Z. rouxii proved to be conspecific with the type strains of P. membranifaciens and K. fluxuum. H. osmophila and L. thermotolerans were detected as minor components of the yeast biota in a non-fermenting wine. The latter was also a minor associate (5\%) of two Zygosaccharomyces species in a young fermenting wine. Very few R. mucilaginosa colonies (1-2\%) were also found in a 3 -year-old aging wine and a last-vintage wine. None of these yeasts were abundant enough to contribute significantly to vinification.

The abundances of C. lactis-condensi and C. zemplinina were comparable to that of $Z$. rouxii, which indicates that these three species were the major yeasts that drove the vinification process of the Essence wines.

\subsection{Why These Yeasts Populate Essence Wines}

The high sugar content of the Essence wines is a very harsh environment that is inhibitory for most yeasts normally participating in grape wine fermentation. The $Z y$ gosaccharomyces and Candida species identified in the Essence samples can cope with this condition because they tolerate high osmotic pressures (low water activity). In a recent comparative examination of over 600 hundred strains, Z. rouxii proved to be the most osmotolerant yeast among 151 species [35]. Its strains were able to grow at glucose concentrations as high as $5.5 \mathrm{M}$. The other Zygosaccharomyces species whose strains were detected in the Essence wines proved to be much less osmotolerant in those tests: the minimal inhibitory concentrations determined for Z. bailii, Z. bisporus and Z. lentus were 3.5-4.25 M, 3.25-4.5 $\mathrm{M}$ and 3.5-4 M, respectively. In light of these data, the higher propagation efficiency of $Z$. rouxii compared to the other Zygosaccharomyces species can be attributed to its higher osmotolerance. Z. bailii and Z. bisporus could only form minor components of the yeast populations because the sugar concentrations $(\approx 3.4 \mathrm{M}$ and $\approx 4.05 \mathrm{M})$ of their wines were only slightly lower than their MIC in the tests of Stratford et al. [35]. The wine from which only Z lentus was isolated had a much lower sugar concentration $(\approx 2.8 \mathrm{M})$ than the MIC ( $3.8 \mathrm{M})$ determined for this species in the aforementioned screening. Somewhat contradictorily with this data, in our tests, all Zygosaccharomyces isolates grew on the agar medium supplemented with $70 \%$ glucose (an MIC higher than $3.9 \mathrm{M}$ ) and in the artificial must containing $30 \%$ glucose and $30 \%$ fructose $(\approx 3.3 \mathrm{M})$.

C. apicola was found to be somewhat more osmotolerant (MIC: $4.5 \mathrm{M}$ ) than the nonrouxii Zygosaccharomyces species by Stratford et al. [35] and more tolerant than Z. rouxii in our microplate assays, yet it was only found as a minor subpopulation in a wine dominated by $Z$. rouxii. The minimal inhibitory concentrations determined by Stratford et al. [35] for Metschnikowia sp. (2.75-3 M), P membranifaciens (2.75-2.9 M), K. fluxuum (2.45 M) and R. mucilaginosa $(2.5-3.5 \mathrm{M})$ were much lower than the sugar concentrations of the Essence wines (except for the wine dominated by Z. lentus). L. thermotolerans, C. lactis-condensi and C. zemplinina were not examined in that study, but in other works, C. zemplinina proved more osmotolerant than Z. bailii [6] and C. lactis-condensi was as tolerant as C. apicola [34]. Little is known about the osmotolerance of $L$. thermotolerans. A recent study reported on more and less osmotolerant $L$. thermotolerans strains, with the former growing faster than the reference $S$. cerevisiae strain in a must containing $48 \%$ sugar $(\approx 2.7 \mathrm{M})$ [97]. Consistent with the literature data on the different osmotolerance of $Z$. rouxii, C. lactis-condensi and C. zemplinina, the average sugar content of the Essence wines dominated by them was $681 \mathrm{~g} \cdot \mathrm{L}^{-1}(\approx 3.8 \mathrm{M}), 588 \mathrm{~g} \cdot \mathrm{L}^{-1}(\approx 3.2 \mathrm{M})$, and $554 \mathrm{~g} \cdot \mathrm{L}^{-1}(\approx 3.1 \mathrm{M})$, respectively. Thus, each of the three major yeasts of the Essence wines seems to have a range of sugar concentrations in which it can be more successful than the other species. However, this tendency was 
not corroborated by the microplate growth assays in which the isolates belonging to these Candida species attained a lower culture density than the Z. rouxii isolates both at 500 and $600 \mathrm{~g} \cdot \mathrm{L}^{-1}$ sugar concentrations during five days of incubation. Nevertheless, none of the concentrations seemed to be restrictive to any of them because, in 12 of the wines, two of them or even all three were present simultaneously.

Because of the low osmotolerance of the species K. fluxuum, Metschnikowia sp., P. membranifaciens, and $R$. mucilaginosa [35], their strains probably could not propagate in the wines from which they were isolated. $R$. mucilaginosa could not grow in the wine either because it is an aerobic basidiomycetous yeast that is unable to gain energy by fermentation. Their presence can be attributed to their ability to form surface pellicles (biofilms). In the cool cellars, the humidity of the air condenses on surfaces and makes them wet. Condensation on the wine surface creates a thin layer of moisture that locally dilutes the wine (reduces its sugar concentration). Within the layer, the cells of these less osmotolerant species can propagate and form biofilms. Many yeast species can form biofilms by aggregating their cells and/or producing pseudohyphae [70]. We found that the K. fluxuum and P. membranifaciens biofilms consisted of adhered cells, and the Metschnikowia sp. and $R$. mucilaginosa isolates also formed pseudohyphae. The best-known examples of biofilm-forming yeasts in wine-making are the so-called "flor strains" of S. cerevisiae that rise to the surface of Sherry wine, where their cells switch from fermentative to oxidative metabolism and oxidise ethanol to precursors of molecules that are responsible for the specific sensorial properties of aging Sherry wines [98]. In a previous study, we found two S. cerevisiae "flor yeast" races (capensis and aceti) in aging Tokaj wines [99]. However, the function of the films of the non-Saccharomyces Essence yeasts may not be gaining energy from ethanol (an unlimited amount of sugar is available) but instead colonising the thin non-toxic environmental niche. Given their low abundance in the yeast biota, they are unlikely to affect the fermentation but may modulate certain sensorial properties of the wine. All low-abundance yeast species found in this study are known to have favourable abilities that can be exploited to improve the wine quality when inoculated in the wine as components of mixed starters (for recent reviews, see, e.g., [11,14,85,100]).

Except for the bottled wine having a low viable yeast number, from which only Z. lentus was isolated, the wines were dominated by one or the other of the species Z. rouxii, C. lactis-condensi and C. zemplinina, but in 12 wines, at least one of these three species was also present as a minor subpopulation. In two of the wines, none of them exceeded $50 \%$. These results indicate that these species competed for dominance. How can one yeast prevail over the others when the conditions are not lethal to any of them (see Section 4.1)? Osmotolerance is undoubtedly an important factor in the competition, but it is by no means the only one. Although C. lactis-condensi is less osmotolerant than Z. rouxii, it dominated (by $93 \%$ ) a wine whose sugar concentration was much higher than the average sugar content of the wines dominated by $Z$. rouxii. On the other hand, only $Z$. rouxii colonies were isolated from a wine containing less sugar than the average sugar contents of the wines dominated by the Candida species. Thus, the actual proportions of the species can be the outcome of the interplay of several factors.

Such factors can be the interspecies interactions in the biota. Yeast strains can interact in many ways, such as by direct physical contact, competition for nutrients and the production and release of inhibitory compounds and toxins (for a review, see [101]). As for the species found in the Essence wines, Z. bailii [102,103] and P. membranifaciens (reviewed in [104]) were previously found to have strains producing killer toxins. Zygocin, the killer factor of a Z. bailii strain, was reported to strongly inhibit the growth of a Z. rouxii strain [103]. Alonso et al. [105] found that certain P. membranifaciens strains isolated from olive brines inhibited the growth of many (but not all) Z. rouxii, Z. bailii and Z. bisporus strains, but the sensitivity of the strains was diverse. The pulcherrimin-producing strains of the pulcherrima clade of Metschnikowia are known to inhibit the growth of other yeasts by immobilising the ferric ions in the environment [96]. A recent study also revealed antagonistic interactions between certain yeasts colonising Tokaj grapes. Metschnikowia sp., 
P. membranifaciens and Z. bailii strains inhibited the growth of L. thermotolerans; L. thermotolerans strains and Metschnikowia sp. isolates had antagonistic effect (growth inhibition) against Pichia membranifaciens [42]. Like the grape yeasts, the Essence isolates also affected each other's growth when tested on agar plates. Two types of interactions were observed: growth inhibition (reduced growth of the lawn around the colony of the other isolate) and crossfeeding (facilitated growth of the lawn around the colony of the other isolate). L. thermotolerans reduced the growth of almost all other isolates involved in the tests, but their own growth was facilitated around the colonies of most other isolates. These interactions can be attributed to competition for nutrients since the two L. thermotolerans isolates also inhibited each other (for inoculation of the colonies on the lawns, a large amount of cells were used, which could deplete the medium of certain nutrients around them very fast). The facilitated growth in the lawn of these isolates around the colonies of other isolates might be due to secreted nutrients and/or growth factors. As for the three major species, only one of the tested C. lactis-condensi strains showed reduced lawn growth around the C. zemplinina and Zygosaccharomyces colonies. Similar interactions could also operate in the Essence wine despite the very different environment in the wine.

One important difference is that the wine is a fluid environment in which the compounds can diffuse much easier. Therefore, we also tested the isolates for growth in mixed liquid cultures. Consistent with the growth reduction effect observed in the plate tests, L. thermotolerans grew much more efficiently than $Z$. rouxii in their mixed culture. Its success can be attributed to the fact that its cells depleted the medium of a substance that was needed by $Z$. rouxii for growth. A similar phenomenon may also account for the dominance of Metschnikowia over Z. rouxii (Metschnikowia depletes the medium of free ferric ions [96]), but interestingly, it did not result in significant growth arrest in the plate tests. Concerning the three major yeast species of the Essence wines, both tested Candida isolates overgrew $Z$. rouxii with a low sugar content but the opposite happened when the sugar content was high. The latter observation was consistent with the microplate results, which measured a higher growth rate for $Z$. rouxii at high sugar concentrations. However, it was less competitive than Z. pseudobailii and H. osmophila in the mixed culture at a high sugar content despite its higher osmotolerance in the microplate tests. When interpreting the experimental results, it should be borne in mind that the grape must is a much more complex environment than the laboratory media.

Interestingly, no Saccharomyces were found among the 3209 isolates, which is an unexpected finding because, in previous studies, we found S. cerevisiae and S. uvarum strains in botrytised grapes and high-sugar Tokaj wines [42,96,99] including Essence wines [49]. The absence of Saccharomyces may have been due to its lower osmotolerance but also to the common practice of treating the wines with sulphite against oxidation at times when the other local wines have completed fermentation but the Essence wines are still in an early stage of fermentation.

\subsection{Intraspecies Clonal Diversity and Segregation}

During the taxonomic identification of the isolates, we noticed that the number of phenotypic clusters was higher than the number of identified species. While isolates belonging to the same cluster were always conspecific, in certain cases, two or even more clusters turned out to belong to the same species. The colony morphology was one of the traits that showed intraspecies diversity. Previous studies reported on heterogeneous colony morphology in yeasts, but colony heterogeneity has not been reported yet for a population of the species found in the Essence wines. In S. cerevisiae, a complex genetic network determines the morphology of colonies, and changes in the network cause changes in the shape of the colonies [106]. Thus, the different morphologies of conspecific yeasts of the Essence wines are also likely to reflect genetic differences. Apart from morphological heterogeneity, the largest group of conspecific isolates, namely, the Z $Z$. rouxii strains, were also heterogeneous in their maltose utilisation, temperature sensitivity, tolerance to ethanol and sulphite (including in acid), $\mathrm{H}_{2} \mathrm{~S}$ production and the growth rate at high sugar 
concentrations in the microplate tests. By definition, the species Z. rouxii is variable in the ability to grow at $37^{\circ} \mathrm{C}$ and on maltose as a carbon source [107]. Consistent with this, we found both heat resistant and heat-sensitive strains, as well as maltose ${ }^{+}$and maltose ${ }^{-}$ strains, among the isolates. Interestingly, there was no correlation between the two traits. No correlation was observed between the other variable strains either. The comparison of the karyotypes, microsatellite-primed RAPD (Random Amplification of Polymorphic DNA) patterns and the mtDNA RFLP (Restriction Fragment Length Polymorphism) patterns revealed an even higher heterogeneity in the genomes of the $Z$. rouxii isolates. Strains that were found to be similar in one test usually differed in other tests, and even strains isolated from the same wine turned out to be different when the results of all tests were taken into consideration. From the high heterogeneity of the isolates, we inferred that the Z. rouxii populations of the Essence wines consisted of subpopulations of different clones. However, when comparing the topologies of the dendrograms, one has to bear in mind that the positions of the strains do not necessarily reflect their real genetic relationships [108]. The populations of the other species also seemed to be heterogeneous because their strains were also diverse in terms of their colony morphology and certain physiological properties. The taxonomic identification of the isolates was based on D1/D2 sequencing because this domain is the most widely used barcode of the ascomycetous yeasts. With the exception of the Metschnikowia isolates and one C. lactis-condensi isolate, all conspecific isolates had identical D1/D2 sequences. However, they may not be uniform over the entire range of LSU (Large Subunit rRNA) genes. Sequencing of the rest of the genes could reveal variable positions and detect correlations between intraspecific morphological and physiological diversity and nucleotide substitutions in these positions.

The clonal heterogeneity could be attributed to multiple (recurrent) infections by heterogeneous populations of the species residing in the winery environment or coming with the harvested grapes. The alternative possibility is that the strains segregate during propagation in the wine. The morphologically different sectors in the Z. rouxii, C. lactiscondensi, L. thermotolerans, Metschnikowia and P. membranifaciens colonies and the segregation of the cultures of the $C$. lactis-condensi isolates into cells producing larger and smaller colonies on the nitrate medium (data not shown) corroborate this possibility. The evolution of strain diversity during vegetative propagation has been observed in both $S$. cerevisiae (e.g., [109-112]) and non-Saccharomyces species [113,114]. In S. cerevisiae, a process referred to as FAGE (fast adaptive genome evolution) was proposed to account for clonal changes in response to the drastically changing environment during fermentation [115]. However, it is not likely that a similar process takes place in the yeast biota of the Essence wines because the composition of these wines does not change significantly during fermentation. As far as we are aware, this is the first report on the clonal structures of Z. rouxii, C. lactis-condensi and C. zemplinina populations in fermenting wines.

\section{Conclusions}

1. The fermentation of high-sugar wine can take place in the absence of Saccharomyces.

2. Instead of Saccharomyces, osmotolerant "spoilage" yeasts can ferment when the sugar concentration is extremely high.

3. In botrytised Tokaj Essence wines of sugar concentrations ranging from 365 to $752 \mathrm{~g} \cdot \mathrm{L}^{-1}$, Zygosaccharomyces rouxii, Candida lactis-condensi and C. zemplinina were the dominating species.

4. The minor species were either other "spoilage" yeasts or less osmotolerant biofilmproducing yeasts.

5. The high phenotypical and molecular (karyotype, mtDNA-RFLP and MSP-PCR) diversity of the conspecific strains indicates that diverse clones of the species coexisted in the wines.

6. Genetic segregation of certain clones and interaction of the species (antagonism and crossfeeding) could also shape the fermenting yeast biota. 
Supplementary Materials: The following are available online at https:/ / www.mdpi.com/2076-2 607/9/1/19/s1: Figure S1. Growth of isolates in artificial must at high concentrations of sugar, Figure S2. UPGMA (Unweighted pair Group Method with Arithmetic means) dendrogram of mtDNA restriction fragment length polymorphism (RFLP) patterns of the Z. rouxii isolates, Figure S3. UPGMA dendrogram of the karyotypes of the Z. rouxii isolates, Table S1. List of taxonomically identified isolates, Table S2. Growth of isolates in artificial must in microplates at high concentrations of sugar.

Author Contributions: Conceptualisation, M.S., H.C., Z.A. and Z.K. methodology, H.C., Z.A., Z.K., K.C. and M.S.; data analysis, M.S.; writing-original draft preparation, M.S.; writing-review, H.C., Z.A., Z.K. and K.C.; funding acquisition, M.S. All authors have read and agreed to the published version of the manuscript.

Funding: This study was funded by the National Research, Development and Innovation Office of Hungary (grant number K-124417).

Data Availability Statement: The data presented in this study are available in Csoma, H.; Kallai, Z.; Antunovics, Z.; Centye, K.; Sipiczki, M.; Vinification without Saccharomyces: interacting osmotolerant and "spoilage" yeast communities in fermenting and ageing botrytized high-sugar wines (Tokaj Essence); Microorganisms and its supplementary material.

Acknowledgments: The authors thank the wineries for allowing them to take samples from the wines. The authors also thank Anita Kovács and Anika Oláh for excellent technical assistance.

Conflicts of Interest: The authors declare no conflict of interest.

\section{References}

1. Fleet, G.H. Wine yeasts for the future. FEMS Yeast Res. 2008, 8, 979-995. [CrossRef] [PubMed]

2. Valera, C.; Borneman, A. Yeasts found in vineyards and wineries. Yeast 2017, 34, 111-128.

3. Morrison-Whittle, P.; Goddard, M.R. From vineyard to winery: A source map of microbial diversity driving wine fermentation. Environ. Microbiol. 2018, 20, 75-84. [CrossRef] [PubMed]

4. Albergaria, H.; Arneborg, N. Dominance of Saccharomyces cerevisiae in alcoholic fermentation processes: Role of physiological fitness and microbial interactions. Appl. Microbiol. Biotechnol. 2016, 100, 2035-2046. [CrossRef]

5. Heard, G.M.; Fleet, G.H. The effects of temperature and $\mathrm{pH}$ on the growth of yeast species during the fermentation of grape juice. J. Appl. Bacteriol. 1988, 65, 23-28. [CrossRef]

6. Tofalo, R.; Chaves-López, C.; Di Fabio, F.; Schirone, M.; Felis, G.E.; Torriani, S.; Paparella, A.; Suzzi, G. Molecular identification and osmotolerant profile of wine yeasts that ferment a high sugar grape must. Int. J. Food Microbiol. 2009, 130, 179-187. [CrossRef]

7. Nisiotou, A.A.; Spiropoulos, A.E.; Nychas, G.J.E. Yeast community structures and dynamics in healthy and Botrytis-affected grape must fermentations. Appl. Environ. Microbiol. 2007, 73, 6705-6713. [CrossRef]

8. De Filippis, F.; Aponte, M.; Piombino, P.; Lisanti, M.T.; Moio, L.; Ercolini, D.; Blaiotta, G. Influence of microbial communities on the chemical and sensory features of Falanghina sweet passito wines. Food Res. Int. 2019, 120, 740-747. [CrossRef] [PubMed]

9. Barata, A.; Santos, S.C.; Malfeito-Ferreira, M.; Loureiro, V. New insights into the ecological interaction between grape berry microorganisms and Drosophila flies during the development of sour rot. Microb. Ecol. 2012, 64, 416-430. [CrossRef] [PubMed]

10. Mills, D.A.; Johannsen, E.A.; Cocolin, L. Yeast diversity and persistence in Botrytis-affected wine fermentations. Appl. Environ. Microbiol. 2002, 68, 4884-4893. [CrossRef] [PubMed]

11. Padilla, B.; Gil, J.V.; Manzanares, P. Past and future of non-Saccharomyces yeasts: From spoilage microorganisms to biotechnological tools for improving wine aroma complexity. Front. Microbiol. 2016, 7, 411. [CrossRef] [PubMed]

12. Malfeito-Ferreira, M.; Silva, A.C. Spoilage yeasts in wine production. In Yeasts in the Production of Wine; Romano, P., Ciani, M., Fleet, G.H., Eds.; Springer Nature: New York, NY, USA, 2019; pp. 375-394.

13. Escott, C.; Loira, I.; Morata, A.; Bañuelos, M.; Suárez-Lepe, J. Wine spoilage yeasts: Control strategy. In Yeast-Industrial Applications; Morata, A., Loira, I., Eds.; InTech: Rijeka, Croatia, 2017; pp. 89-116.

14. Ivit, N.N.; Longo, R.; Kemp, B. The effect of non-Saccharomyces and Saccharomyces non-cerevisiae yeasts on ethanol and glycerol levels in wine. Fermentation 2020, 6, 77. [CrossRef]

15. Morata, A.; Escott, C.; Bañuelos, M.A.; Loira, I.; Fresno, J.M.D.; González, C.; Suárez-Lepe, J.A. Contribution of non-Saccharomyces yeasts to wine freshness. A review. Biomolecules 2019, 10, 34. [CrossRef] [PubMed]

16. Curtin, C.D.; Varela, C.; Borneman, A. Harnessing improved understanding of Brettanomyces bruxellensis biology to mitigate the risk of wine spoilage. Aust. J. Grape Wine Res. 2015, 21, 680-692. [CrossRef]

17. Agnolucci, M.; Tirelli, A.; Cocolin, L.; Toffanin, A. Brettanomyces bruxellensis yeasts: Impact on wine and winemaking. World. J. Microbiol. Biotechnol. 2017, 33, 180. [CrossRef]

18. Jermini, M.F.G.; Geiges, O.; Schmidt-Lorenz, W. Detection, isolation and identification of osmotolerant yeasts from high-sugar products. J. Food Prot. 1987, 50, 468-472. [CrossRef] 
19. Gordon, J.L.; Wolfe, K.H. Recent allopolyploid origin of Zygosaccharomyces rouxii strain ATCC 42981. Yeast 2008, 25, 449-456. [CrossRef]

20. Solieri, L.; Cassanelli, S.; Croce, M.A.; Giudici, P. Genome size and ploidy level: New insights for elucidating relationships in Zygosaccharomyces species. Fungal Genet. Biol. 2008, 45, 1582-1590. [CrossRef]

21. Wrent, P.; Rivas, E.M.; Peinado, J.M.; de Silóniz, M.I. Zygosaccharomyces rouxii strains CECT 11923 and Z. rouxii CECT 10425 : Two new putative hybrids? Int. J. Food Microbiol. 2017, 241, 7-14. [CrossRef]

22. Braun-Galleani, S.; Ortiz-Merino, R.A.; Wu, Q.; Xu, Y.; Wolfe, K.H. Zygosaccharomyces pseudobailii, another yeast interspecies hybrid that regained fertility by damaging one of its MAT loci. Fems Yeast Res. 2018, 18, foy079. [CrossRef]

23. Csoma, H.; Sipiczki, M. Taxonomic reclassification of Candida stellata strains reveals frequent occurrence of Candida zemplinina in wine fermentation. Fems Yeast Res. 2008, 8, 328-336. [CrossRef] [PubMed]

24. Sipiczki, M. Candida zemplinina sp. nov., an osmotolerant and psychrotolerant yeast that ferments sweet botrytized wines. Int. J. System. Evol. Microbiol. 2003, 53, 2079-2083. [CrossRef] [PubMed]

25. Granchi, L.; Ganucci, D.; Messini, A.; Rosellini, D.; Vincenzini, M. Oenological properties of Hanseniaspora osmophila and Kloeckera cortices from wines produced by spontaneous fermentations of normal and dried grapes. FEMS Yeast Res. 2002, 2, $403-407$. [PubMed]

26. Passoth, V.; Fredlund, E.; Druvefors, U.Ä.; Schnürer, J. Biotechnology, physiology and genetics of the yeast Pichia anomala. FEMS Yeast Res. 2006, 6, 3-13. [CrossRef]

27. Shimizu, Y.; Watanabe, M. Effects of yeast strains and environmental conditions on formation of organic acids in must during fermentation. J. Fermen. Technol. 1981, 59, 27-32.

28. Sponholz, W.R.; Dittrich, H.H. Die Bildung von SO2 bindenden Gärungsnebenprodukten, höheren Alkoholen und Estern bei einigen Reinzuchthefestämmen und bei einigen für die Weinbereitung wichtigen "wilden" Hefen. Wein-Wiss 1974, 29, 301-314.

29. Kántor, A.; Petrová, J.; Hleba, L.; Kluz, M.; Kačániová, M. Determination of spoilage yeasts in different red and white wines. Sci. Pap. Anim. Sci. Biotechnol. 2016, 49, 57-65.

30. Sánchez-Rubio, M.; Guerrouj, K.; Taboada-Rodríguez, A.; López-Gómez, A.; Marín-Iniesta, F. Control of native spoilage yeast on dealcoholized red wine by preservatives alone and in binary mixtures. J. Food Sci. 2017, 82, 2128-2133. [CrossRef]

31. Romano, P.; Suzzi, G. Origin and production of acetoin during wine yeast fermentation. Appl. Environ. Microbiol. 1996, 62, 309-315. [CrossRef]

32. Chandra, M.; Oro, I.; Ferreira-Dias, S.; Malfeito Ferreira, M. Effect of ethanol, sulfur dioxide and glucose on the growth of wine spoilage yeasts using response surface methodology. PLoS ONE 2015, 10, e0128702. [CrossRef]

33. Scarr, M.P.; Rose, D. Study of osmophilic yeasts producing invertase. J. Gen. Microbiol. 1966, 45, 9-16. [CrossRef]

34. Tokuoka, K.; Ishitani, T. Minimum water activities for the growth of yeasts isolated from high-sugar foods. J. Gen. Appl. Microbiol. 1991, 37, 111-119. [CrossRef]

35. Stratford, M.; Steels, H.; Novodvorska, M.; Archer, D.B.; Avery, S.V. Extreme osmotolerance and halotolerance in food-relevant yeasts and the role of glycerol-dependent cell individuality. Front. Microbiol. 2019, 9, 3238. [CrossRef] [PubMed]

36. Combina, M.; Daguerre, C.; Massera, A.; Mercado, L.; Sturm, M.E.; Ganga, A.; Martinez, C. Yeast identification in grape juice concentrates from Argentina. Lett. Appl. Microbiol. 2008, 46, 192-197. [CrossRef] [PubMed]

37. Rojo, M.; Arroyo Lopez, F.; Lerena, M.; Mercado, L.; Torres, A.; Combina, M. Effects of pH and sugar concentration in 'Zygosaccharomyces rouxii' growth and time for spoilage in concentrated grape juice at isothermal and nonisothermal conditions. Food Microbiol. 2013, 38, 143-150. [CrossRef] [PubMed]

38. Wang, H.X.; Hu, Z.Q.; Long, F.Y.; Niu, C.; Yuan, Y.H.; Yue, T.L. Characterization of osmotolerant yeasts and yeast-like molds from apple orchards and apple juice processing plants in China and investigation of their spoilage potential. J. Food Sci. 2015, 80, M1850-M1860. [CrossRef] [PubMed]

39. Loureiro, V.; Malfeito-Ferreira, M. Spoilage yeasts in the wine industry (review). Int. J. Food Microbiol. 2003, 86, 23-50. [CrossRef]

40. Thompson, S. Microbiological spoilage of high-sugar products. In Compendium of the Microbiological Spoilage of Foods and Beverages: Food Microbiology and Food Safety; Sperber, W.H., Doyle, M.P., Eds.; Springer: New York, NY, USA, 2009; pp. 301-324.

41. Magyar, I. Botrytized wines. Adv Food Nutr. Res. 2011, 63, 147-206.

42. Sipiczki, M. Overwintering of vineyard yeasts: Survival of interacting yeast communities in grapes mummified on vines. Front. Microbiol. 2016, 7, 212. [CrossRef]

43. Donèche, B.J. Botrytized wines. In Wine Microbiology and Biotechnology; Fleet, G.H., Ed.; Harwood Academic Publishers: Chur, New York, NY, USA, 1993; pp. 327-353.

44. Sipiczki, M. Yeasts in botrytised wine making. In Yeasts in the Production of Wine; Romano, P., Ciani, M., Fleet, G.H., Eds.; Springer Nature: New York, NY, USA, 2019; pp. 229-261.

45. Greger, M. Notes on the Pure or Natural Wines of Hungary, Their Properties and Uses; Jas. Truscott \& Sons: London, UK, 1879.

46. Allen, H.W. The Romance of Tokay; Berry Bross: London, UK, 1928.

47. Jackson, R.S. Wine Science; Academic Press: San Diego, CA, USA, 2000.

48. Eftimová, Z.; Eftimová, J.; Balážová, L'. Antioxidant activity of Tokaj Essence. Slov. J. Food Sci. 2018, 12, 323-329. [CrossRef]

49. Csoma, H.; Sipiczki, M. Taxonomic investigation of the yeast biota of botrytized grapes and "Essence" in the Tokaj wine region. In Book of Abstracts, 8th International Enology Symposium; Vigne et Vin Publications Internationales: Villenave d'Ornon, France, 2007 ; p. 174. 
50. Duarte, F.L.; Pimentel, N.H.; Teixeira, A.; Fonseca, A. Saccharomyces bacillaris is not a synonym of Candida stellata: Reinstatement as Starmerella bacillaris comb. nov. Antonie Van Leeuwenhoek 2012, 102, 653-658. [CrossRef] [PubMed]

51. Santos, A.R.O.; Leon, M.P.; Barros, K.O.; Freitas, L.F.D.; Hughes, A.F.S.; Morais, P.B.; Lachance, M.-A.; Rosa, C.A. Starmerella camargoi f.a., sp. nov., Starmerella ilheusensis f.a., sp. nov., Starmerella litoralis f.a., sp. nov., Starmerella opuntiae f.a., sp. nov., Starmerella roubikii f.a., sp. nov. and Starmerella vitae f.a., sp. nov., isolated from flowers and bees, and transfer of related Candida species to the genus Starmerella as new combinations. Int. J. Syst. Evol. Microbiol. 2018, 68, 1333-1343. [PubMed]

52. Zara, S.; Mannazu, I. Detection, quantification, and identification of yeast in winemaking. In Yeasts in the Production of Wine; Romano, P., Ciani, M., Fleet, G.H., Eds.; Springer Nature: New York, NY, USA, 2019; pp. 81-115.

53. Stefanini, I.; Cavalieri, D. Metagenomic approaches to investigate the contribution of the vineyard environment to the quality of wine fermentation: Potentials and difficulties. Front. Microbiol. 2018, 9, 991. [CrossRef] [PubMed]

54. Hierro, N.; Esteve-Zarzoso, B.; González, Á.; Mas, A.; Guillamón, J.M. Real-time quantitative PCR (QPCR) and reverse transcription-QPCR for detection and enumeration of total yeasts in wine. Appl. Environ. Microbiol. 2006, 72, 7148-7155. [CrossRef]

55. Wang, C.; Esteve-Zarzoso, B.; Cocolin, L.; Mas, A.; Rantsiou, K. Viable and culturable populations of Saccharomyces cerevisiae, Hanseniaspora uvarum and Starmerella bacillaris (synonym Candida zemplinina) during Barbera must fermentation. Food Res. Int. 2015, 78, 195-200. [CrossRef]

56. Vendrame, M.; Manzano, M.; Comi, G.; Bertrand, J.; Iacumin, L. Use of propidium monoazide for the enumeration of viable Brettanomyces bruxellensis in wine and beer by quantitative PCR. Food Microbiol. 2014, 42, 196-204. [CrossRef]

57. Kurtzman, C.P.; Fell, J.W.; Boekhout, T.; Robert, V. Methods for isolation, phenotypic characterization and maintenance of yeasts. In The Yeasts. A Taxonomic Study; Kurtzman, C.P., Fell, J.W., Boekhout, T., Eds.; Elsevier: Amsterdam, The Netherlands, 2011 ; pp. 87-110.

58. Wickerham, L.J. Taxonomy of Yeasts; Techn. Bull. 1029; U.S. Deptartment of Agriculture: Washington, DC, USA, 1951.

59. Commission Regulation (EEC) No 2676/90 of 17 September 1990 determining Community methods for the analysis of wines, Commission of the European Communities. Official Journal of the European Communities L 272, 03/10/1990 P. 0001-0192. Available online: https:/ / op.europa.eu/en/publication-detail/- / publication/6528497d-1ece-4355-ab08-c73b3242f7ee (accessed on 20 December 2020).

60. Nguyen, H.V.; Lepingle, A.; Gaillardin, C.A. Molecular typing demonstrates homogeneity of Saccharomyces uvarum strains and reveals the existence of hybrids between S. uvarum and S. cerevisiae, including the S. bayanus type strain CBS 380 . Syst. Appl. Microbiol. 2000, 23, 71-85. [CrossRef]

61. Baleiras-Couto, M.M.; Hartog, B.J.; Huis in't Veld, J.H.J.; Hofstra, H.; van der Vossen, J.M.B.M. Identification of spoilage yeasts in a food-production chain by microsatellite polymerase chain reaction fingerprinting. Food Microbiol. 1996, 13, 59-67. [CrossRef]

62. Pavel, A.B.; Vasile, C.I. PyElph-A software tool for gel images analysis and phylogenetics. BMC Bioinform. 2012, 13, 9. [CrossRef]

63. Dice, L.R. Measurements of the amount of ecologic association between species. Ecology 1945, 26, 297-302. [CrossRef]

64. Garcia-Vallve, S.; Palau, J.; Romeu, A. Horizontal gene transfer in glycosyl hydrolases inferred from codon usage in Escherichia coli and Bacillus subtilis. Mol. Biol. Evol. 1999, 9, 1125-1134. [CrossRef] [PubMed]

65. Tofalo, R.; Schirone, M.; Torriani, S.; Rantsiou, K.; Cocolin, L.; Perpetuini, G.; Suzzi, G. Diversity of Candida zemplinina strains from grapes and Italian wines. Food Microbiol. 2012, 29, 18-26. [CrossRef] [PubMed]

66. Kurtzman, C.P.; Robnett, C.J. Identification and phylogeny of ascomycetous yeasts from analysis of nuclear large subunit (26S) ribosomal DNA partial sequences. Antonie Van Leeuwenhoek 1998, 73, 331-371. [CrossRef] [PubMed]

67. Bader, O. Fungal species identification by MALDI-ToF mass spectrometry. Methods Mol. Biol. 2017, 1508, $323-337$.

68. Sipiczki, M. Metschnikowia pulcherrima and related pulcherrimin-producing yeasts: Fuzzy species boundaries and complex antimicrobial antagonism. Microorganisms 2020, 8, 1029. [CrossRef]

69. Riedl, R.; Futterer, J.; Goderbauer, P.; Michel, M.; Jacob, F.; Hutzler, M. Combined yeast biofilm screening-Characterization and validation of yeast related biofilms in a brewing environment with combined cultivation and specific real-time PCR screening of selected indicator species. J. Am. Soc. Brew. Chem. 2019, 77, 99-112. [CrossRef]

70. Zara, G.; Budroni, M.; Mannazzu, I.; Fancello, F.; Zara, S. Yeast biofilm in food realms: Occurrence and control. World J. Microbiol. Biotechnol. 2020, 36, 134. [CrossRef]

71. Pitt, J.I.; Hocking, A.D. Fungi and Food Spoilage; Academic Press Australia: Sydney, Australia, 1985.

72. Stratford, M.; Capell, C.J. Soft drinks. Microbiology. In Encyclopedia of Food Sciences and Nutrition, 2nd ed.; Caballero, B., Trugo, L., Finglas, P.M., Eds.; Academic Press: San Diego, CA, USA, 2003; pp. 5358-5366.

73. Kuanyshev, N.; Adamo, G.M.; Porro, D.; Branduardi, P. The spoilage yeast Zygosaccharomyces bailii: Foe or friend? Yeast 2017, 34, 359-370. [CrossRef]

74. Perrusquía-Luévano, S.; Cano-Herrera, M.S.; Guigón-López, C.; Avitia-Talamantes, M.D.C.; Torres-Torres, C.; Villalpando, I. Microbiology of high-sugar must fermentation by novel yeasts from the chihuahuan desert. FEMS Yeast Res. 2019, 19, foy099. [CrossRef]

75. Fleet, G.H.; Lafon-Lafourcade, S.; Ribéreau-Gayon, P. Evolution of yeasts and lactic acid bacteria during fermentation and storage of Bordeaux wines. Appl. Environ. Microbiol. 1984, 48, 1034-1038. [CrossRef]

76. Divol, B.; Lonvaud-Funel, A. Evidence for viable nonculturable yeasts in Botrytis-affected wine. J. Appl. Microbiol. 2005, 99, 85-93. [CrossRef] [PubMed] 
77. Mateus, D.; Sousa, S.; Coimbra, C.; Rogerson, F.S.; Simões, J. Identification and characterization of non-Saccharomyces species isolated from port wine spontaneous fermentations. Foods 2020, 9, 120. [CrossRef] [PubMed]

78. Minarik, E.; Jungova, E.; Emeriaud, M. Fruktophile Hefen und deren Einfluss auf süsse Naturweine. Wein-Wiss 1978, 33, 42-47.

79. Domizio, P.; Romani, C.; Lencioni, L.; Comitini, F.; Gobbi, M.; Mannazzu, I.; Ciani, M. Outlining a future for non-Saccharomyces yeasts: Selection of putative spoilage wine strains to be used in association with Saccharomyces cerevisiae for grape juice fermentation. Int. J. Food Microbiol. 2011, 147, 170-180. [CrossRef] [PubMed]

80. Romano, P.; Fiore, C.; Paraggio, M.; Caruso, M.; Capece, A. Function of yeast species and strains in wine flavour. Int. J. Food Microbiol. 2003, 86, 169-180. [CrossRef]

81. Romano, P.; Suzzi, G. Potential use for Zygosaccharomyces species in winemaking. J. Wine Res. 1993, 4, 87-94. [CrossRef]

82. Garavaglia, J.; Schneider, R.C.S.; Mendes, S.D.C.; Welke, J.E.; Zini, C.A.; Caramão, E.B.; Valente, P. Evaluation of Zygosaccharomyces bailii BCV 08 as a co-starter in wine fermentation for the improvement of ethyl esters production. Microbiol. Res. 2015, 173, 59-65. [CrossRef]

83. Suh, S.O.; Gujjari, P.; Beres, C.; Beck, B.; Zhou, J. Proposal of Zygosaccharomyces parabailii sp. nov. and Zygosaccharomyces pseudobailii sp. nov., novel species closely related to Zygosaccharomyces bailii. Int. J. Syst. Evol. Microbiol. 2013, 63, 1922-1929. [CrossRef]

84. Barata, A.; Seborro, F.; Belloch, C.; Malfeito-Ferreira, M.; Loureiro, V. Ascomycetous yeast species recovered from grapes damaged by honeydew and sour rot. J. Appl. Microbiol. 2008, 104, 1182-1191. [CrossRef]

85. Vicente, J.; Ruiz, J.; Belda, I.; Benito-Vázquez, I.; Marquina, D.; Calderón, F.; Santos, A.; Benito, S. The genus Metschnikowia in enology. Microorganisms 2020, 8, 1038. [CrossRef]

86. Steels, H.; James, S.A.; Roberts, I.N.; Stratford, M. Zygosaccharomyces lentus: A significant new osmophilic, preservative-resistant spoilage yeast, capable of growth at low temperature. J. Appl. Microbiol. 1999, 87, 520-527. [CrossRef] [PubMed]

87. Bokulich, N.A.; Hwang, C.F.; Liu, S.; Boundy-Mills, K.L.; Mills, D.A. Profiling the yeast communities of wine fermentations using terminal restriction fragment length polymorphism analysis. Am. J. Enol. Vitic. 2012, 63, 185-194. [CrossRef]

88. Antunovics, Z.; Csoma, H.; Sipiczki, M. Molecular and genetic analysis of the yeast flora of botrytized Tokaj wines. Bull. De L'oiv (Off. Int. De La Vigne Et Du Vin Paris) 2003, 76, 380-397.

89. Csoma, H.; Sipiczki, M. Investigation of the yeast microflora of "Tokaj essence". In Proceedings of the Abstract Book, 1st FEMS Congress of European Microbiologists, Ljubljana, Slovenia, 29 June-3 July 2003; p. 213.

90. Magyar, I.; Bene, Z. Morphological and taxonomic study on mycobiota of noble rotted grapes in the Tokaj wine district. Acta Aliment. 2006, 35, 237-246. [CrossRef]

91. Masneuf-Pomarede, I.; Juquin, E.; Miot-Sertier, C.; Renault, P.; Laizet, Y.; Salin, F.; Alexandre, H.; Capozzi, V.; Cocolin, L.; ColonnaCeccaldi, B.; et al. The yeast Starmerella bacillaris (synonym Candida zemplinina) shows high genetic diversity in winemaking environments. FEMS Yeast Res. 2015, 15, fov045. [CrossRef]

92. Urso, R.; Rantsiou, K.; Dolci, P.; Rolle, L.; Comi, G.; Cocolin, L. Yeast biodiversity and dynamics during sweet wine production as determined by molecular methods. FEMS Yeast Res. 2008, 8, 1053-1062. [CrossRef]

93. Li, J.; Hu, W.; Huang, X.; Xu, Y. Investigation of yeast population diversity and dynamics in spontaneous fermentation of Vidal blanc icewine by traditional culture-dependent and high-throughput sequencing methods. Food Res. Int. 2018, 112, 66-77. [CrossRef]

94. Englezos, V.; Giacosa, S.; Rantsiou, K.; Rolle, L.; Cocolin, L. Starmerella bacillaris in winemaking: Opportunities and risks. Curr. Opin. Food Sci. 2017, 17, 30-35. [CrossRef]

95. Pawlikowska, E.; James, S.A.; Breierova, E.; Antolak, H.; Kregiel, D. Biocontrol capability of local Metschnikowia sp. isolates. Antonie Van Leeuwenhoek 2019, 112, 1425-1445. [CrossRef]

96. Sipiczki, M. Metschnikowia strains isolated from botrytized grapes antagonize fungal and bacterial growth by iron depletion. Appl. Environ. Microbiol. 2006, 72, 6716-6724. [CrossRef]

97. Morales, M.L.; Fierro-Risco, J.; Ríos-Reina, R.; Ubeda, C.; Paneque, P. Influence of Saccharomyces cerevisiae and Lachancea thermotolerans co-inoculation on volatile profile in fermentations of a must with a high sugar content. Food Chem. 2019, 276, 427-435. [CrossRef] [PubMed]

98. Pozo-Bayón, M.; Moreno-Arribas, M.V. Sherry wines. Adv. Food Nutr. Res. 2011, 63, 17-40.

99. Miklos, I.; Sipiczki, M.; Benko, Z. Osmotolerant yeasts isolated from Tokaj wines. J. Basic. Microbiol. 1994, 6, 379-385. [CrossRef] [PubMed]

100. Benito, S. The impacts of Lachancea thermotolerans yeast strains on winemaking. Appl. Microbiol. Biotechnol. 2018, 102, 6775-6790. [CrossRef]

101. Bordet, F.; Joran, A.; Klein, G.; Roullier-Gall, C.; Alexandre, H. Yeast-yeast interactions: Mechanisms, methodologies and impact on composition. Microorganisms 2020, 8, 600. [CrossRef]

102. Radler, F.; Herzberger, S.; Schönig, I.; Schwarz, P. Investigation of a killer strain of Zygosaccharomyces bailii. J. Gen. Microbiol. 1993, 139, 495-500. [CrossRef]

103. Weiler, F.; Schmitt, M.J. Zygocin, a secreted antifungal toxin of the yeast Zygosaccharomyces bailii, and its effect on sensitive fungal cells. FEMS Yeast Res. 2003, 3, 69-76. [CrossRef]

104. Belda, I.; Ruiz, J.; Alonso, A.; Marquina, D.; Santos, A. The biology of Pichia membranifaciens killer toxins. Toxins 2017, 9 , 112. [CrossRef] 
105. Alonso, A.; Belda, I.; Santos, A.; Navascués, E.; Marquina, D. Advances in the control of the spoilage caused by Zygosaccharomyces species on sweet wines and concentrated grape musts. Food Control 2015, 51, 129-134. [CrossRef]

106. Voordeckers, K.; De Maeyer, D.; van der Zande, E.; Vinces, M.D.; Meert, W.; Cloots, L.; Ryan, O.; Marchal, K.; Verstrepen, K.J. Identification of a complex genetic network underlying Saccharomyces cerevisiae colony morphology. Mol. Microbiol. 2012, 86, 225-239. [CrossRef]

107. James, S.; Stratford, M. Zygosaccharomyces Barker (1901). In The Yeasts. A Taxonomic Study; Kurtzman, C.P., Fell, J.W., Boekhout, T., Eds.; Elsevier: Amsterdam, The Netherlands, 2011; pp. 937-947.

108. Csoma, H.; Acs-Szabo, L.; Papp, L.A.; Sipiczki, M. Application of different markers and data-analysis tools to the examination of biodiversity can lead to different results: A case study with Starmerella bacillaris (synonym Candida zemplinina) strains. Fems Yeast Res. 2018, 18, foy021. [CrossRef] [PubMed]

109. Longo, E.; Vezinhet, F. Chromosomal rearrangements during vegetative growth of a wild strain of Saccharomyces cerevisiae. Appl. Environ. Microbiol. 1993, 59, 322-326. [CrossRef] [PubMed]

110. Schütz, M.; Gafner, J. Analysis of yeast diversity during spontaneous and induced alcoholic fermentations. J. Appl. Bacteriol. 1993, 75, 551-558. [CrossRef]

111. Nadal, D.; Carro, D.; Fernández, L.J.; Pina, B. Analysis and dynamics of the chromosomal complement of wild sparkling-wine yeast strains. Appl. Environ. Microbiol. 1999, 65, 1688-1695. [CrossRef] [PubMed]

112. Ramirez, M.; Vinagre, A.; Ambrona, J.; Molina, F.; Maqueda, M.; Robello, J.E. Genetic instability of heterozygous, hybrid, natural wine yeasts. Appl. Environ. Microbiol. 2004, 70, 4686-4691. [CrossRef]

113. Schütz, M.; Gafner, J. Dynamics of the yeast strain population during spontaneous determined by CHEF gel electrophoresis. Lett. Appl. Microbiol. 1994, 19, 253-259. [CrossRef]

114. Povhe-Jemec, K.; Cadez, N.; Zagorc, T.; Bubic, V.; Zupec, A.; Raspor, P. Yeast population dynamics in five spontaneous fermentations of Malvasia must. Food Microbiol. 2001, 18, 247-259. [CrossRef]

115. Sipiczki, M. Diversity, variability and fast adaptive evolution of the wine yeast (Saccharomyces cerevisiae) genome-A review. Ann. Microbiol. 2011, 61, 85-93. [CrossRef] 